San Jose State University

SJSU ScholarWorks

Master's Theses

Master's Theses and Graduate Research

Summer 2018

\title{
The Effect of Automating Routine Tasks on Air Traffic Controller Conflict Detection Performance
}

Lauren Claudatos

San Jose State University

Follow this and additional works at: https://scholarworks.sjsu.edu/etd_theses

\section{Recommended Citation}

Claudatos, Lauren, "The Effect of Automating Routine Tasks on Air Traffic Controller Conflict Detection Performance" (2018). Master's Theses. 4933.

DOI: https://doi.org/10.31979/etd.q3dt-95n9

https://scholarworks.sjsu.edu/etd_theses/4933

This Thesis is brought to you for free and open access by the Master's Theses and Graduate Research at SJSU ScholarWorks. It has been accepted for inclusion in Master's Theses by an authorized administrator of SJSU ScholarWorks. For more information, please contact scholarworks@sjsu.edu. 
THE EFFECT OF AUTOMATING ROUTINE TASKS ON AIR TRAFFIC CONTROLLER CONFLICT DETECTION PERFORMANCE

\author{
A Thesis \\ Presented to \\ The Faculty of the Department of Psychology \\ San José State University
}

In Partial Fulfillment

Of the Requirements for the Degree

Master of Arts

by

Lauren E. Claudatos

August 2018 
(C) 2018

Lauren E. Claudatos

ALL RIGHTS RESERVED 
The Designated Thesis Committee Approves the Thesis Titled

THE EFFECT OF AUTOMATING ROUTINE TASKS ON AIR TRAFFIC CONTROLLER CONFLICT DETECTION PERFORMANCE

by

Lauren E. Claudatos

APPROVED FOR THE DEPARTMENT OF PSYCHOLOGY

SAN JOSÉ STATE UNIVERSITY

August 2018

Sean Laraway, Ph.D

Department of Psychology

Susan Snycerski, Ph.D

Department of Psychology

Joey Mercer, M.S.

Research Psychologist, HumanSystems Integration Division, National Aeronautics and Space Administration 


\title{
ABSTRACT \\ THE EFFECT OF AUTOMATING ROUTINE TASKS ON AIR TRAFFIC CONTROLLER CONFLICT DETECTION PERFORMANCE
}

\author{
by Lauren E. Claudatos
}

The growing demand for air transportation necessitates the integration of automated support tools to assist air traffic controllers in managing the increase in number of flights. Using archival data from a human-in-the-loop simulation, the current study examined the potential consequence of integrating automated support on eight retired air traffic controllers' performance and workload in current and projected future levels of air traffic. Two-way repeated measures ANOVA were used to examine workload and conflict detection performance across two levels of simulated air traffic density and two levels of automated routine task support. The participant controllers reported significantly higher workload and exhibited a non-significant decrease in conflict detection performance when managing a higher number of aircraft. The decrease in conflict detection performance reached significance only when participant controllers were not assisted by automation. In contrast, participant controllers were slowest to detect conflicts while managing the least number of aircraft and assisted by automation. The results of the current study are mixed; we conclude that automation of routine tasks has the potential to mitigate the increased workload and decreased performance experienced as the number of aircraft increases, certainly over no assistance, but that it may also be disruptive in certain circumstances, such as during low air traffic levels where the controllers may experience underload. More research is needed to identify appropriate levels of automation to achieve the same level of safety seen in today's air traffic control system. 


\section{TABLE OF CONTENTS}



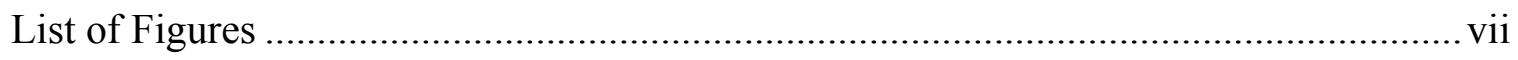

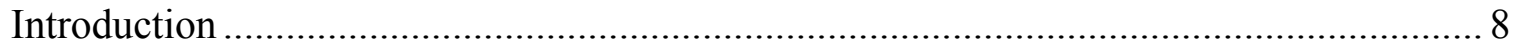

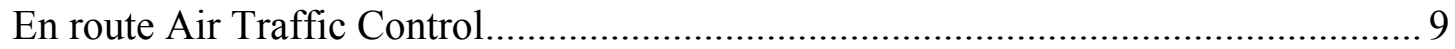

Handoffs. ............................................................................................. 10

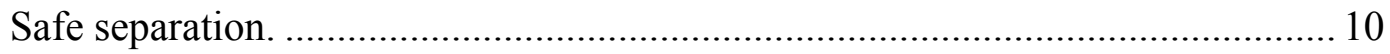

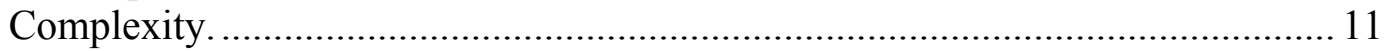

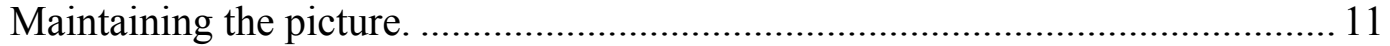

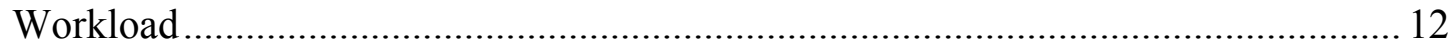

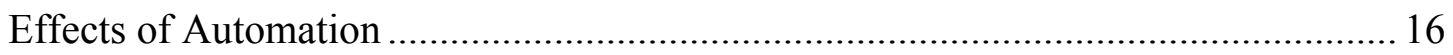

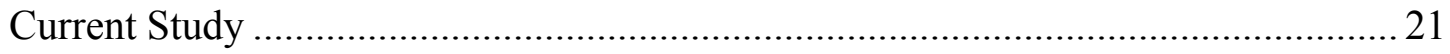

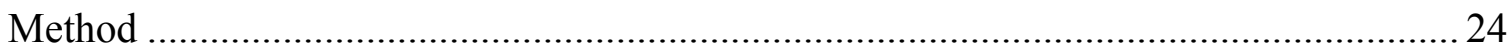

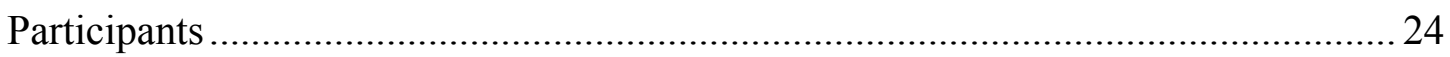

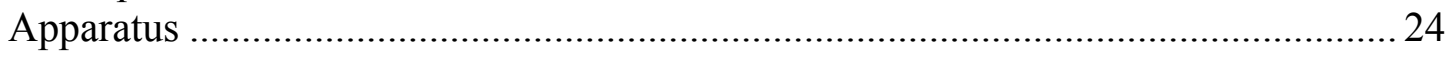

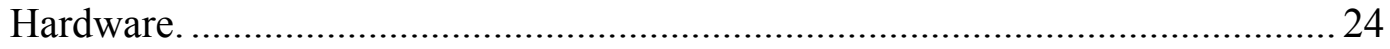

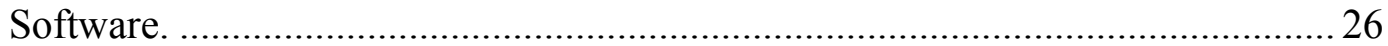

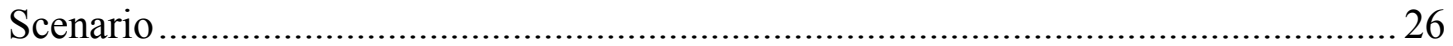

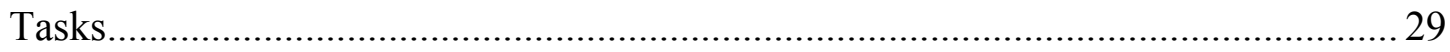

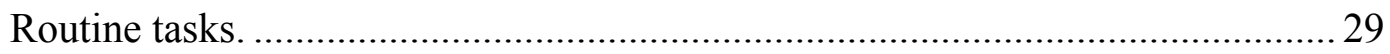

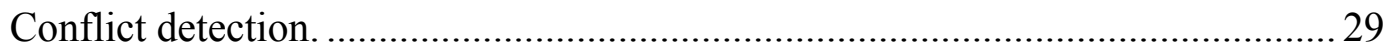

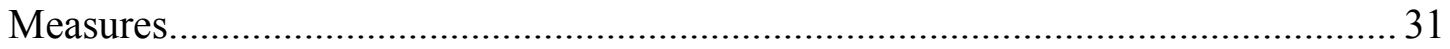

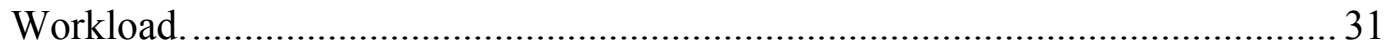

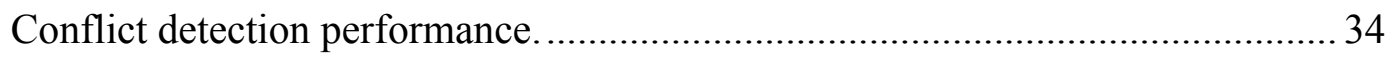

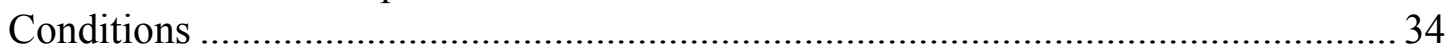

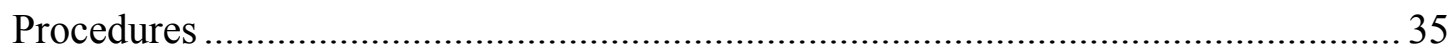

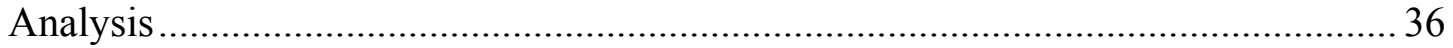

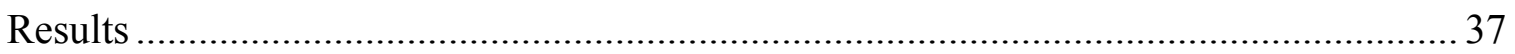

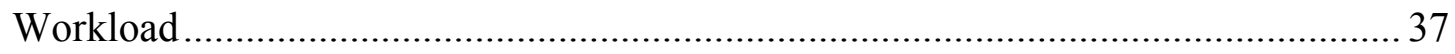

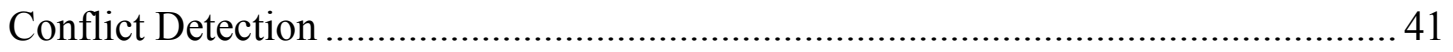



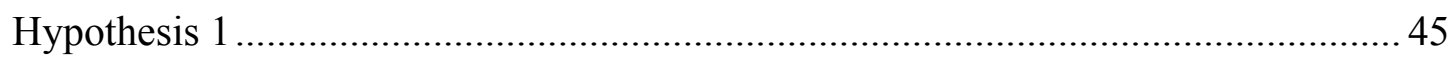

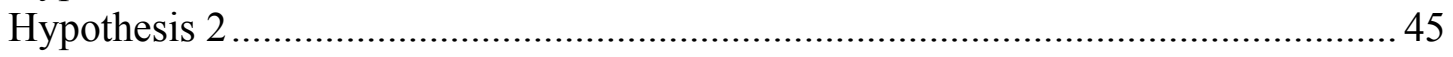

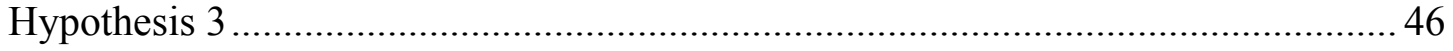

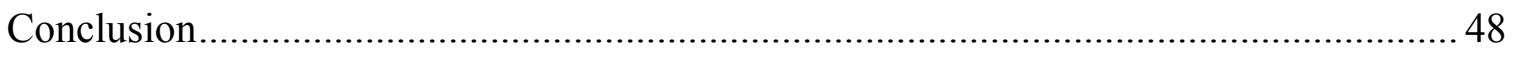

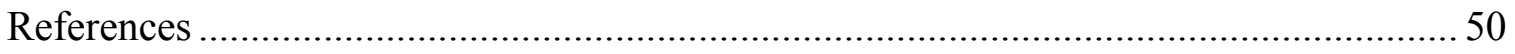




\section{LIST OF TABLES}

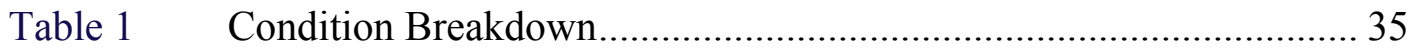

Table 2 Descriptive Statistics of Workload Ratings .......................................... 40

Table 3 Simple Main Effects for Each Level of Routine Tasks and Density for Workload .......................................................................... 40

Table 4 Descriptive Statistics of ANT Scores ................................................... 42

Table 5. Simple Main Effects for Each Level of Routine Tasks and Density for Score............................................................................... 42 


\section{LIST OF FIGURES}

Figure 1. Airspace Operations Lab experimental setup.................................25

Figure 2. Illustration of the Cleveland ARTCC sector used in the original

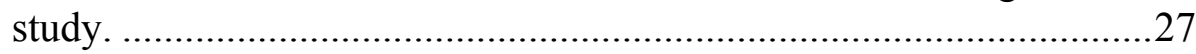

Figure 3. Example participant controller display during simulation. ................28

Figure 4. Example of aircraft color changes according to command used.........30

Figure 5. Example of the Air Traffic Workload Input Technique (ATWIT) implemented in MACS. .....................................................................32

Figure 6. Participant brief with description of workload experienced and corresponding workload level. .......................................................33

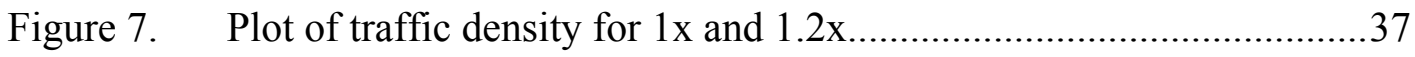

Figure 8. Mean workload (ATWIT) across the two levels of density and

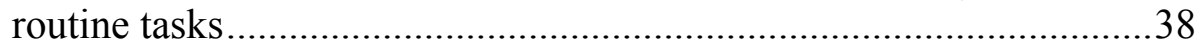

Figure 9. Frequency of workload by routine task and workload by traffic

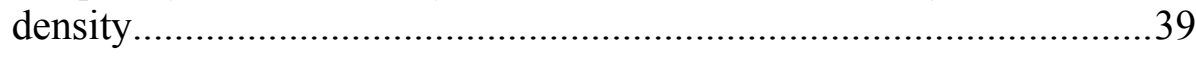

Figure 10. Mean ANT across the two levels of density and routine tasks............41

Figure 11. Conflict detection rate by routine tasks and by density....................43

Figure 12. Conflict detection rate by condition. ............................................43

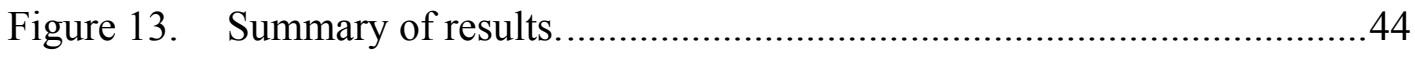




\section{Introduction}

Domestic and international travelers from the U.S. reached a record high of 965 million passengers in 2017, compared to 853.1 million during 2014 (Bureau of Transportation Statistics, 2016b, 2016a). The flights carrying those passengers were guided through the airspace in a safe and orderly flow by air traffic controllers, who do so with minimal automated technological assistance. Any increases to air traffic levels heighten the complexity of the air traffic control (ATC) task, and therefore increase the demands placed on each individual air traffic controller (Department of Transportation \& FAA, 2016). The Next Generation Air Transportation System, or NextGen, is a systemwide implementation of new ATC technology that addresses the growing concerns associated with the anticipated impact of increased levels of air traffic (Department of Transportation \& FAA, 2016). With NextGen, air traffic controllers will be able to use automation in various degrees to support their decision-making. For example, one of the key components of the NextGen initiative is En Route Automation Modernization, or ERAM, which provides faster and more accurate information by integrating multiple sources of aircraft position data, as well as automation of certain warnings and alerts (FAA Office of NextGen, 2016). ERAM is also a platform for digital, rather than voice, communication (also known as data comm or datalink) between pilots, air traffic controllers, and dispatchers (FAA Office of NextGen, 2016).

However, Sipe and Moore (2009) suggest that even with the advancements made so far, the air traffic levels of the future cannot be safely managed with today's ATC system, in part, due to air traffic controller workload; the limitations of air traffic controllers' 
ability to safely manage aircraft is related to the objective and subjective demands placed on them by those aircraft. Automation has been proposed as a means of reducing controller workload so that as the number of aircraft increases, the controller may focus more on critical tasks, like keeping aircraft separated, and focus less on simple, repetitive tasks, like routine handoffs.

It is assumed that safety is paramount to the Federal Aviation Administration (FAA), and therefore new technologies are not adopted until they have been properly vetted to meet performance and safety standards. If the goal of automation is to replace, augment, or assist in ATC tasks so as to improve overall performance in a human-centered system, it is important to understand which tasks should be automated and when. It is therefore important to take into account the many concurrent sub-tasks an air traffic controller performs today and to consider how automating some tasks can impact the performance of those that are done manually by the controller. This was the focus of the current study.

\section{En Route Air Traffic Control}

Aircraft in high-altitude, controlled airspace are typically under the responsibility of the US National Airspace System's Air Route Traffic Control Center (ARTCC) facilities. To help accommodate airspace demands while not overloading any one air traffic controller, the ARTCC, referencing air traffic characteristics, divides its airspace into sectors. Busier airspace will have smaller sectors whereas less dense airspace will have larger sectors.

Handoffs. Air traffic controllers are responsible for all aircraft in their sector. It is imperative that pilots stay in contact with the air traffic controller while flying through a 
sector. As aircraft fly in to or out of a sector, pilots and controllers follow protocols for transferring communication and control to the adjacent sector's controller in a process called a handoff. As an aircraft approaches the boundary between two sectors, the transferring controller will initiate the handoff to the receiving controller; the receiving controller will accept the handoff; the transferring controller will give the pilot the receiving controller's frequency; and finally, the pilot will contact the receiving controller on the new frequency. This process gives receiving controllers authority and responsibility of the aircraft so that they may issue any instructions and clearances deemed necessary for an orderly transit through their sector. When the aircraft approaches the end of the receiving controller's sector, the handoff process starts again for transfer to the next sector.

Safe separation. Keeping aircraft safely separated from one another is the highestpriority task for an air traffic controller while managing the flow of traffic through their sector (Bureau of Labor Statistics, 2016). While continuously scanning a sector, air traffic controllers look for aircraft on a trajectory that will put them within $5 \mathrm{nmi}$ laterally or 1,000 ft vertically of another aircraft (Federal Aviation Administration, Mission support services, 2017). This is called a conflict, and once identified, air traffic controllers carefully consider the surrounding traffic and will issue a clearance (e.g., altitude vertical or lateral maneuver) to one or more involved aircraft. To simplify the traffic in their sector and to ease coordination with other sectors, controllers employ heuristics, such as procedural separation, whereby aircraft follow odd-numbered altitudes if travelling east-bound, and even-numbered altitudes if travelling west-bound (Nolan, 
2010). Even with using these rules, the sector is far from sterile: conflicts can still occur as aircraft cross paths headed to various destinations, and climb or descend through different altitudes. As controllers work to maintain safe operations in their sector, they must constantly scan their sector in order to identify potential conflicts.

Complexity. One can consider an individual sector as having a particular nature (driven by its unique shape, location, etc.), and, at any point in time, as aircraft progress through the sector, the sector can produce particular traffic situations. These elements interact in various ways, necessitating varying amounts of effort on behalf of the controller in order to keep aircraft separated. This combination of sector and traffic characteristics is also known as the construct of air traffic complexity. Air traffic complexity is based on a number of factors, such as air traffic density, traffic flow patterns, and the relationship between the aircraft in the sector at any given time (Kopardekar, Prevot, \& Jastrzebski, 2009; Majumdar \& Ochieng, 2002). A sector's complexity is a major contributor to an air traffic controller's workload, with density, number of conflicts, and number of maneuvers available to resolve conflicts being the biggest contributors (Kopardekar et al., 2009). Research in air traffic control must consider the effects of complexity on subjective workload and how changes in workload affect performance.

Maintaining the picture. Air traffic controllers are able to keep track of all this information by using mental shortcuts, much like a chess player; rather than evaluating each individual piece on the board (or aircraft in the sector), an experienced chess player uses patterns and the relationship between the pieces on the board to form a mental 
"picture" of the game. In air traffic control, the "picture" can be thought of as the synthesis of all the aircraft into meaningful patterns and relationships reducing the overall cognitive load remembering each piece of information would have. Air traffic controllers refer to keeping track of the information required to do their job as "maintaining the picture," enabling them to rapidly assess situations as they unfold, anticipate changes in the complexity of the air traffic, and select strategies.

In a cognitive task analysis of expert air traffic controllers, Seamster, Redding, Cannon, Ryder, and Purcell (1993) found that air traffic controllers use a combination of sector characteristics, tasks, events, domain knowledge, and experience to build and update a mental model of the current sector. As the characteristics of the sector change over time, air traffic controllers use important cues (e.g. changes in traffic density, discovery of a potential conflict, etc.) to re-evaluate the current situation and, if need be, switch to a different style of managing the air traffic (Seamster et al., 1993). This reevaluation of the situation and change in strategy has been studied in expert air traffic controllers, who use these skills to effectively regulate their workload, particularly in anticipation of increased workload (Seamster et al., 1993).

\section{Workload}

Air traffic controllers must take into account a great deal of information when managing the airspace and be constantly on the lookout for potential conflicts. This task becomes considerably more difficult when the number of aircraft, and therefore the level of complexity, increases. In an effort to reduce workload, controllers are known to change their strategy of managing the air traffic (Seamster et al., 1993). With the 
projected increase in air traffic, it is important that we understand the impact of increased task and workload on how well controllers perform their tasks, in addition to the role of task management in the regulation of workload.

Glaster et al. (2001) examined the effects of traffic density and the presence or absence of conflicts on controller workload and performance in a human-in-the-loop (HITL) simulation. In this study, participant controllers managed simulated air traffic with and without potential conflicts in medium and heavy traffic levels. Their primary tasks were conflict detection, verbally identifying an aircraft pair as a potential conflict, and accepting incoming and making outgoing handoffs as aircraft enter and leave the sector, respectively. Participant controllers were not responsible for resolving or deconflicting the aircraft involved in the potential conflicts. Performance for conflict detection included the frequency of hit versus missed detections in addition to the advanced notification time (ANT), which is defined as the elapsed time between the detection and the loss of separation. The authors qualify higher ANT scores with better performance. Handoff performance was measured as the response time to engage in the handoff task and the number of completed versus missed handoffs. Not surprisingly, Glaster et al. found that traffic levels had a significant impact on conflict detection and workload, with more missed conflicts and higher workload reported in the heavy trafficlevel condition. Additionally, in heavy traffic levels, participant controllers took longer to detect conflicts, indicated by lower average ANT scores. Interestingly, the presence or absence of potential conflicts did not have an effect on workload. However, when 
conflicts were present, participant controllers took significantly longer to respond to a handoff, which illustrates the prioritization of attentional resources and task management.

Lee, Mercer, and Callantine (2007) examined strategy changes in response to increased air traffic of air traffic controllers in a HITL simulation. Retired air traffic controllers managed a simulated en route sector with current-day air traffic levels and again with higher than current-day levels. Lee et al. found when air traffic levels increased, air traffic controllers shed less essential tasks and did so in anticipation of increased workload. Specifically, controllers reduced the number of times they viewed routes and adjusted or toggled datablocks (the latter usually in an effort to de-clutter their display). Then, during periods of low traffic levels, controllers would pick up previously shed tasks. Another finding was that when traffic increased, participant controllers changed their route/altitude clearance strategy by engaging in more route clearances during low workload and more altitude clearances during high workload. Given that route clearances require two separate instructions (send the aircraft off-course, then put the aircraft back on course when appropriate), whereas altitude clearances only require one instruction, presumably controllers not only consider the sector/traffic situation, but perhaps also weigh their own capacity to perform certain tasks when deciding which actions to make. Route clearances seems to have a strategic advantage during low traffic levels, possibly as a means of keeping the controller engaged, whereas the shift to altitude clearances during periods of high traffic levels functions as a workload-reducing approach to the same task (Lee et al., 2007; Seamster et al., 1993). 
Willems and Truitt (1999) also examined the relationship between workload and performance in air traffic controllers with the addition of task engagement in a HITL simulation. Participant controllers actively managed or passively monitored simulated aircraft in low and high traffic levels. Willems and Truitt found that although workload increased as a function of traffic level, workload was higher when controllers were actively managing aircraft, regardless of traffic level. Ratings from observing subject matter experts indicated changes in the controllers' subjective performance as the traffic level increased. In low traffic levels, controllers exhibited more effective planning, communication, and use of equipment. Like Lee et al. (2007), Willems and Truitt also found that controllers used significantly more altitude changes during high traffic loads. A concerning finding in their study is that participant controllers in the monitoring condition scored lower on a recall task and measure of awareness, despite no change in subjective reports of awareness. This implies that the participant controllers may be unaware of their own decline in awareness when passively monitoring.

Metzger and Parasuraman (2001) hypothesized that being engaged through direct manipulation and interaction with the air traffic will result in better awareness than that resulting from the less engaging task of passive monitoring, especially as traffic level increases. In their HITL simulation, participant controllers were asked to detect conflicts in addition to performing routine tasks (e.g., handoffs) while managing two levels of traffic density (moderate and high). In the active-control condition, controllers would issue resolutions to the conflicting aircraft and could manage traffic manually at any time. Controllers in the passive monitoring condition were restricted to conflict detection 
without issuing resolutions, while still being responsible for routine tasks. Metzger and Parasuraman measured conflict detection performance using the ANT metric and a count of hits and misses. Workload was measured using the NASA-TLX, an offline measure of workload assessed at the end of a condition. Controllers experienced a significant increase in workload when managing traffic in the high traffic level conditions, but there was no difference in workload reported between active control and passive monitoring conditions, which contradicts the results of Willems and Truitt (1999). Additionally, participant controllers detected the same number of conflicts in both active control and passive monitoring but took much longer to detect conflicts when passively monitoring high traffic levels, indicated by lower average ANT score. Metzger and Parasuraman (2001) claim that this decline in conflict detection performance is the "cost of passive monitoring" (p. 524), suggesting that with increased traffic levels, participant controllers who were actively controlling were already engaged and had developed a better picture of the situation in the sector.

\section{Effects of Automation}

The constant stream of decisions air traffic controllers must make defines air traffic control. Informed by air traffic control research, Parasuraman, Sheridan, and Wickens (2000) proposed a parsimonious, human-centered model of automation, consisting of four stages representing human information processing. The four stages are information acquisition, information analysis, decision selection, and action implementation. Each of these captures the general category of functions that can be allocated to automation as well as the degree to which that task is automated. Parasuraman et al. recommended that 
integration of automation into a system should consider things like workload, situation awareness, complacency, skill degradation, and out-of-the-loop unfamiliarity. Complacency is the phenomena wherein operators will gradually accept the results of the automated process as correct without verifying its accuracy. Skill degradation and outof-the-loop unfamiliarity are essentially the problem of task disengagement; investigating the cost in performance when a human operator must suddenly make a decision or take manual control in an otherwise automated system. These authors suggested that things like routine tasks are ideal candidates for automation, as they have very little cost if something goes wrong and have the potential to substantially alleviate a potentially unmanageable task load.

Using the classification of automation proposed by Parasuraman et al., (2000), Kaber, Perry, Segall, and Sheik-Nainar (2007) studied the effects of automated support of information acquisition, information analysis, decision-making, and action implementation on operator performance in a simulated air traffic control task. They utilized a mixed-factorial with five levels of task support (no support/manual and four types of automated support) as the between-subjects variable and two levels of air traffic density (low and high) as the within-subject variable. Operator performance was measured as the number of aircraft cleared (i.e. handed off to next sector), potential conflicts, and losses of separation. Workload was measured using the NASA-TLX and performance on a secondary task (gauge-monitoring). Kaber et al. found an increase in performance when participants were provided automated support for action implementation; their performance was better when handoffs were automated compared 
to conditions without automation support and in conditions where automation supported other functions. Conflict detection performance was the best in the information analysis and decision-making conditions, both of which alerted participants to potential conflicts. Of the conditions where conflict detection was not automated (including the manual condition), participants detected the most conflicts in the action implementation condition. One limitation of the Kaber et al. study is that the participants were college students and not air traffic controllers. Given that air traffic controllers are a highly specialized population, the use of students and not air traffic controllers as participants limits the application of the results.

Also using the model proposed by Parasuraman et al. (2000), Manzey, Reichenbach, and Onnasch (2012) hypothesized that greater levels of decision support automation would result in better performance and a decrease in workload. In addition to subjective workload, performance on a supervisory control task and a secondary task were measured under three levels of automation and manual performance. The supervisory control task consisted of monitoring life support system values for deviations and indicating a possible source of a fault. A fault was a scripted failure of a subsystem, which needed to be correctly identified, diagnosed, and repaired all while manually controlling the subsystem. In the conditions with decision support automation, participants were assisted by the automation in the diagnosis and repair of the faulty subsystems. Manzey et al. found that as more of the decision-making task was automated, performance on the supervisory control task improved and overall workload decreased. However, when suddenly returning to manual performance, such as during a system fault, participants 
with the highest level of decision support automation suffered the sharpest increase in workload. Participants in the highest level of automation spent the least amount of time verifying the automation.

Balfe, Sharples, and Wilson (2015) examined the effects of level of decision support automation on performance, workload, and task management of railway signalers in nominal and increased task load. This part-task, HITL simulation took place in a replica rail signaling workstation used for training, which was equipped with a visual display unit (VDU) based signaling system and an automated tool replacing the mechanical switches for directing railway traffic. The VDU based system also provided a platform for integrating other automated tools. In the Balfe et al. study, six participant signalers managed railway traffic in three conditions: unassisted (using only the VDU), with the ability to set automatically approved routes, and with Automatic Route Setting (ARS), which is an advanced decision support tool that uses system information to plan safe routes and detect potential route conflicts. A scripted disruption occurred halfway through each scenario thereby increasing the task load for the remainder of the scenario. Balfe et al., found that when assisted by automation, the majority of signalers received higher performance scores and reported lower average workload. The authors point out that although workload was consistently lower for ARS-assisted signalers, they had the sharpest increase in workload following a disruption, which the authors attribute to the effort expended to re-engage with the system. They also point out that two of the six participants performed better with the auto-routes than with support from ARS, illustrating the importance of individual differences. These individual differences were 
also apparent in the task management strategies used by signalers. As part of the task management measure, the authors distinguished between active and passive monitoring. They defined passive monitoring behavior as viewing the VDU while sitting back and active monitoring as viewing while sitting forward. Signalers supported by ARS spent the most time passively monitoring, but the authors point out a large number of individual differences with some electing to spend time actively monitoring or disengaging completely (taking a break). Following the disruption however, signalers spent about the same amount of time actively monitoring regardless of condition.

Prevot, Homola, and Mercer (2008) measured the change in performance, workload, and task management of air traffic controllers and students as they managed traffic manually or assisted by automation in three levels of air traffic density. Retired air traffic controllers and student participants managed current-day, high (double that of currentday), and very high (triple that of current-day) levels of air traffic in a combined sector (i.e., two adjacent sectors). For the duration of the study, participants were responsible for conflict resolutions, which were done manually or with automated assistance. In the manual conflict resolution condition, participants had access to a trial-planning tool, which assisted them in planning conflict-free maneuvers, which could be sent directly to pilots via data link. In the interactive condition, participants had access to the trialplanning tool and the Auto-Resolver, an automated tool that would provide conflict-free maneuvers, which could be modified by the participants if they chose. Finally, Prevot et al. included a closed-loop condition where the traffic was managed entirely by the automation for all three traffic densities. 
Prevot et al., (2008) found that both student participants and retired air traffic controllers reported an increasingly higher average workload as they worked higher traffic levels. Participants were only able to manage the highest traffic levels with the assistance of the Auto-Resolver; when only using the trial-planning tool in the highest density condition, participants resolved the fewest conflicts, incurred the most amount of delay, and reported the highest average workload. The authors suggested that because conflict detection was automated in all conditions, the change in workload is associated with the planning and execution of the resolution. When retired air traffic controllers could use the Auto-Resolver, they did so nearly every time, with only a slight decrease in the lowest density. This is compared to the student participants, who used the AutoResolver about half the time in the lowest density. Prevot et al., compared the average flight delay of the fully automated conditions to the ones with human participants and found that, when given the bandwidth, the retired air traffic controllers were able to provide more efficient resolutions than the Auto-Resolver, resulting in less average delay.

\section{Current Study}

A human-centered approach to automation considers the context and human operator in the design and measures of performance. As more automation is introduced, there are clear benefits in the reduction of workload but the benefits to performance are more complex. Automation of decision support tasks reduces workload and can increase performance. However, by having a task completely automated, there is a risk that manual performance will degrade or that attentive monitoring/verifying of the automation will decrease. This can be dangerous if the automation fails when performing a safety- 
critical function, which is why Parasuraman et al. (2000) recommend taking level-of-risk into account when selecting which task(s) to automate. Additionally, decision support automation affects task management and is susceptible to individual differences and traffic management style. When automating tasks that are normally done manually, it is important to consider how that will affect the operators' task management and performance of concurrent tasks in addition to monitoring or interacting with the automated task. The aim of the current study was to contribute to the understanding of how automation of a routine task affects air traffic controller performance of higher priority, concurrent tasks. Specifically, this study attempts to answer: how does the automation of routine tasks affect conflict detection performance?

Mentioned previously, Parasuraman et al. (2000) suggested routine tasks are ideal candidates for automation as they have little cost if something goes wrong, and their absence could substantially alleviate a potentially unmanageable task load. Prevot et al. (2012) echoed the idea of leaving the routine to the automation and the off-nominal or non-routine to the human operator, especially in the safety-critical context of air traffic control. Kaber et al. (2007) reported automation of handoffs significantly reduced workload compared to automation of other tasks. Additionally, automation of handoffs reduced the average number of aircraft that lost separation compared to the fully manual condition. However, Kaber et al. did not use air traffic controllers as participants in their research.

This archival study expands upon this research to better understand the effect of automation of routine tasks for air traffic controllers. Taking into account the intricate 
relationship between how each controller uses the current state of the sector to inform task management and workload reduction strategies, the hypotheses are as follows: (a) Controllers' subjective workload will increase when traffic density increases; (b) in a current-day traffic density, controllers' subjective workload will be reduced when routine tasks are automated; and (c) in a higher traffic density, controllers' conflict detection performance will be better when routine tasks are automated compared to when routine tasks are manual. The data analyzed were collected as part of a series of studies on future automation concepts in air traffic control. 


\section{Method}

This study used a subset of part-task HITL simulation data previously collected as part of a larger research effort by the NASA Ames Airspace Operations Laboratory (AOL) (Prevot et al., 2014) to examine function allocation in the context of separation assurance. The original study, referred to as Human-Automation Conflict Detection (HACD), is reported in Edwards, Homola, Mercer, and Claudatos (2016). HACD was operated under Protocol HRII-14-09, "Next Generation Air Transportation System (NextGen)," as approved by NASA's Human Research Institutional Review Board (HRIRB).

\section{Participants}

Participants consisted of eight (one female and seven male) retired air traffic controllers from Oakland Air Route Traffic Control Center (ZOA ARTCC), ages 50 to 69 , with an average of 24.9 years of experience. Four additional retired controllers from ZOA ARTCC and 12 pseudo-pilots participated as confederates. The 12 pseudo-pilots consisted of aviation students and general aviation pilots. Collectively, the aviation students and general aviation pilots had an average of over 500 hours of experience as pseudo-pilots.

\section{Apparatus}

Hardware. The standard lab equipment used by all participants consisted of a Dell desktop computer with a mouse and keyboard. A tablet computer used for hosting/interacting with the VoIP software was provided at each of the participants' stations. Each participant was provided a headset and a push-to-talk switch connected to 
the VoIP system. The pseudo-pilot stations had two standard desktop monitors placed side by side while the confederate controllers had one large desktop monitor. Input and display devices used in current ATC facilities were set up for each of the eight participant controller stations. This consisted of a monitor, DSR keyboard, trackball, Keypad Selection Device (KSD), and a foot pedal that could be used in place of the headset's push-to-talk switch. For each participant station, all equipment necessary was arranged at a desk and each one was provided a chair. See Figure 1 for the arrangement of these stations in the lab.

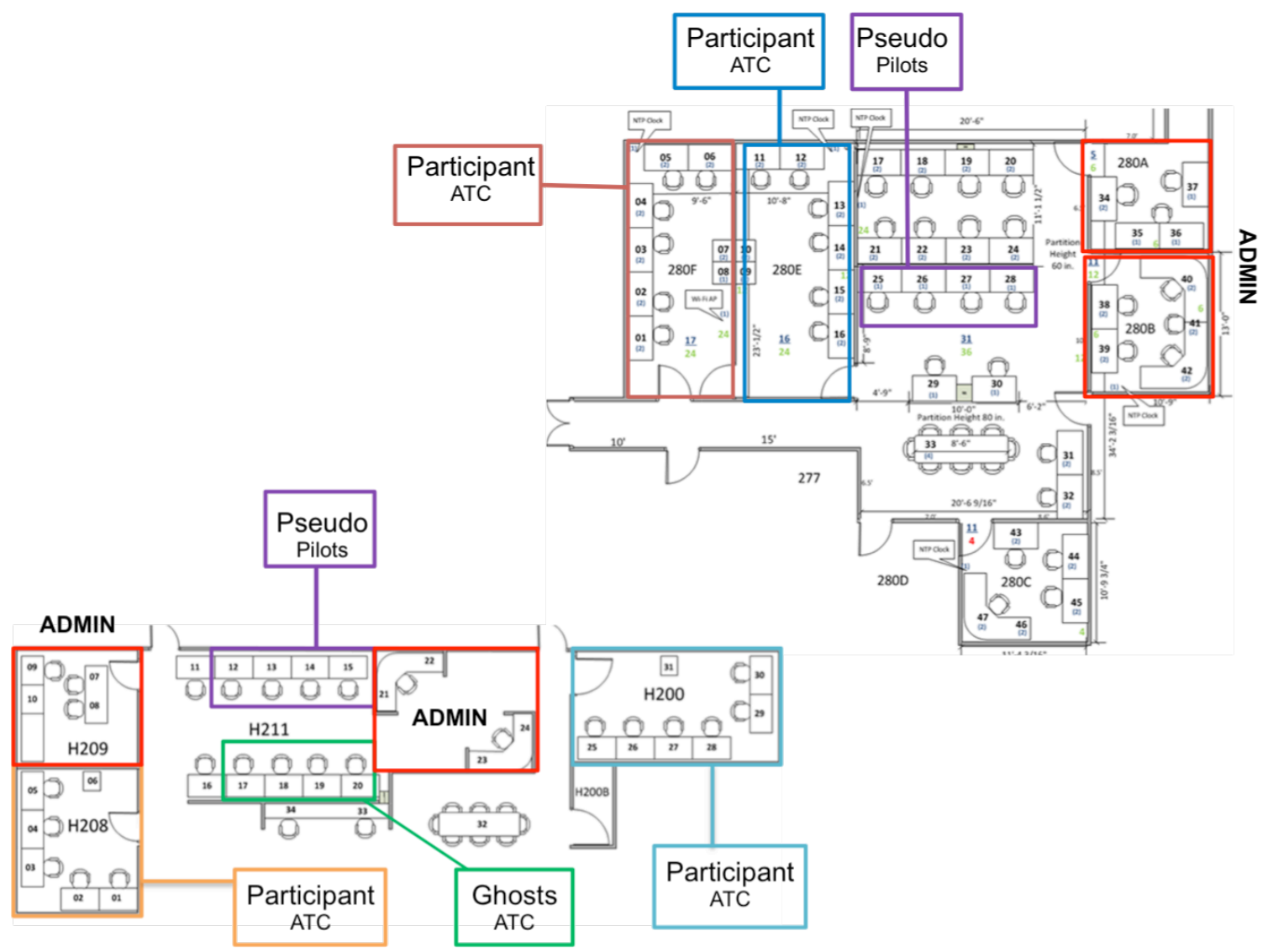

Figure 1. Airspace Operations Lab experimental setup. 
Software. Each of the participant stations ran the Multi Aircraft Control System (MACS), which is a JAVA program developed in the AOL at NASA Ames Research Center for HITL simulations of air traffic operations. The AOL's infrastructure enabled researchers to run multiple isolated instances of the experimental air traffic control scenarios simultaneously. For a more detailed description of MACS and the different configurations, see Prevot (2002) and Prevot and Mercer (2007). Lastly, each station ran Camtasia, a screen-recording software application, to capture both screen and audio recordings throughout the study.

\section{Scenario}

Participant controllers were responsible for a mix of level and transitioning air traffic in a single high-altitude sector in Cleveland ARTCC (Figure 2). Figure 3 is an example of a participant controller's display. Air traffic consisted of aircraft equipped with a flight management system (FMS) and datalink for data communication. Each aircraft was also equipped with automatic dependent surveillance-broadcast (ADS-B) for reporting speed and altitude. Participant controllers could assume a required navigation performance (RNP) of 1 or better for the lateral navigation performance of each aircraft. 


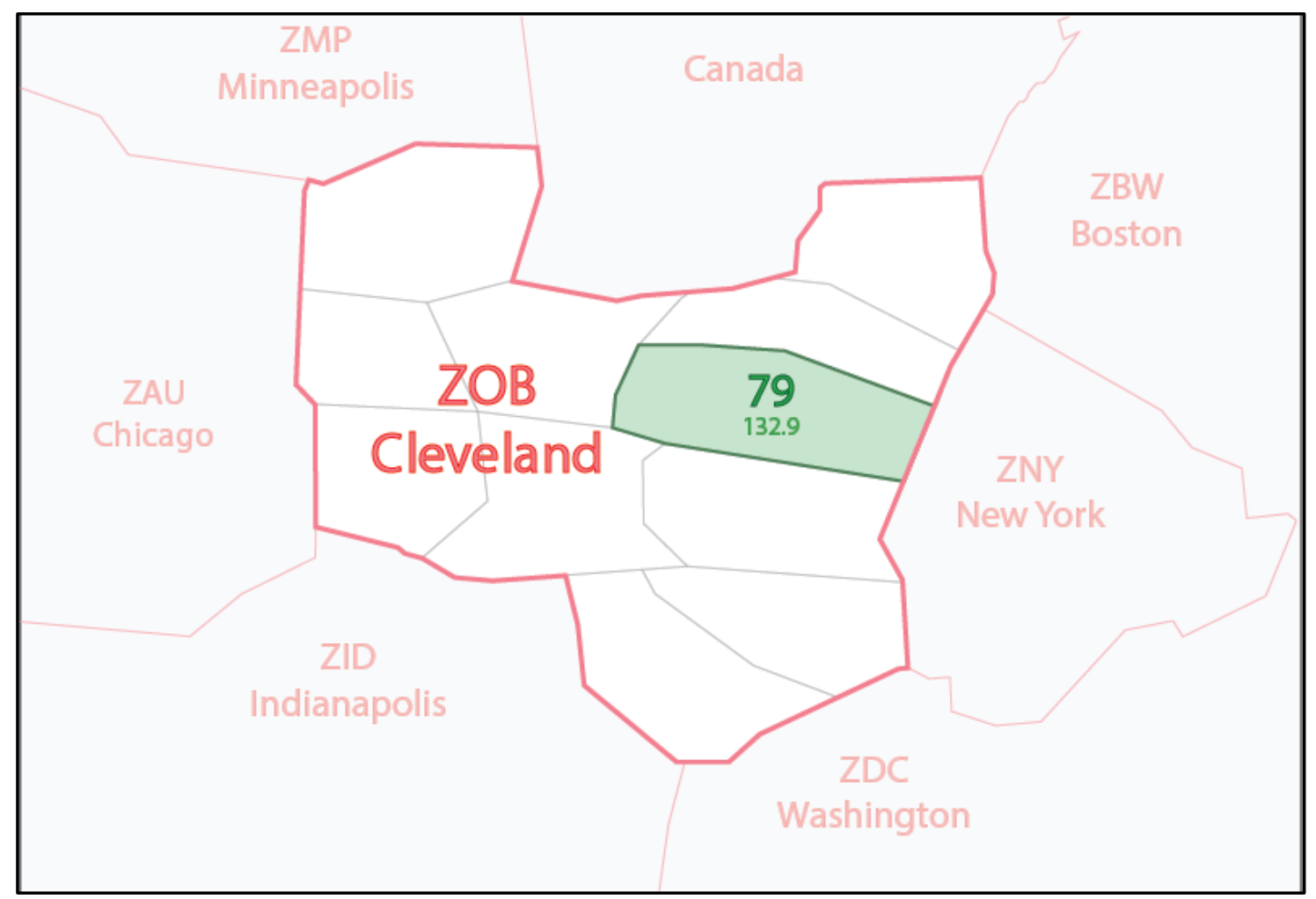

Figure 2. Illustration of the Cleveland ARTCC sector used in the original study. 


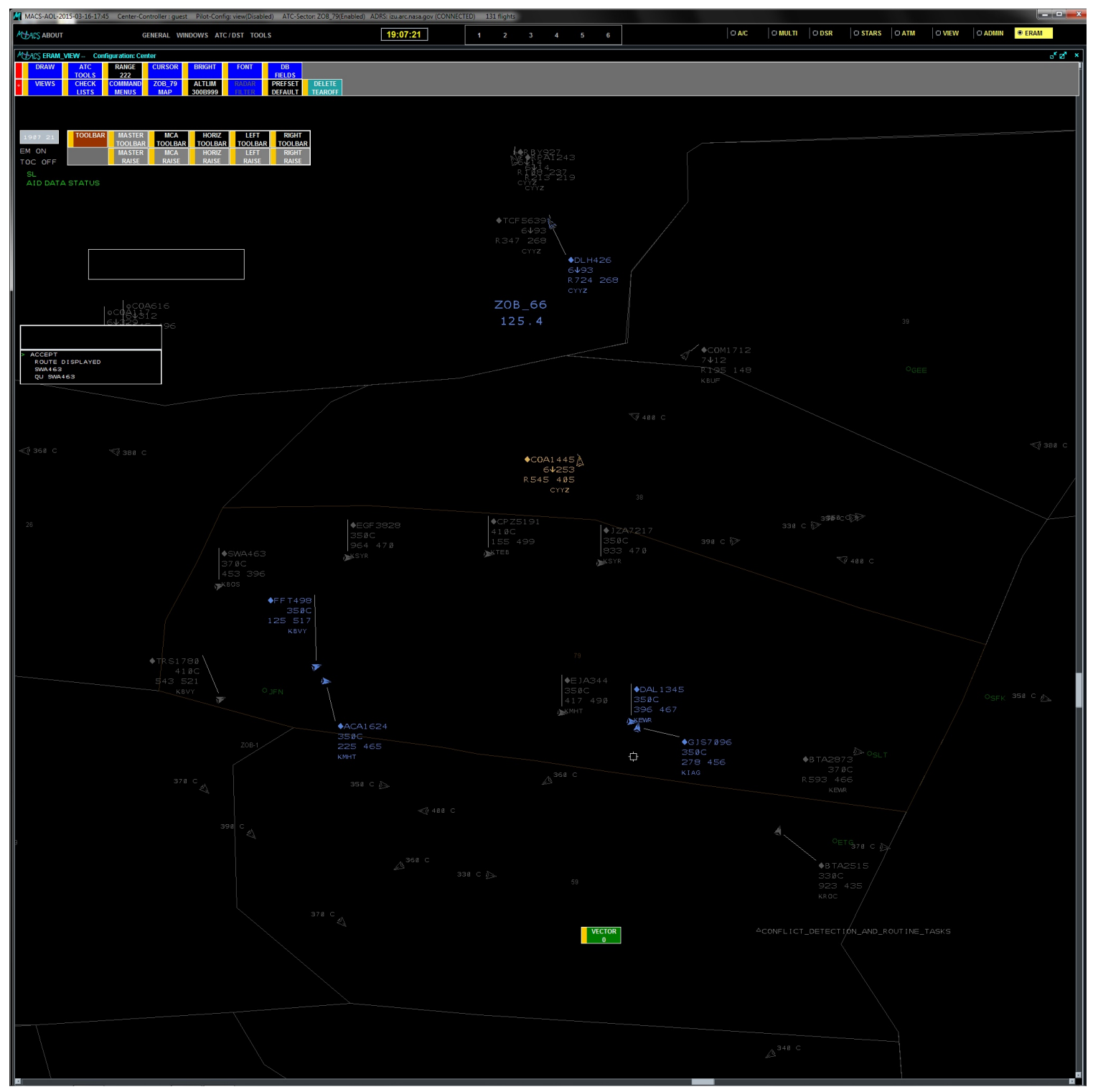

Figure 3. Example participant controller display during simulation. 


\section{Tasks}

Routine tasks. Participant controllers were tasked with check-ins and accepting handoffs for incoming aircraft, and initiating handoffs and frequency changes for outgoing aircraft. Each time an aircraft entered or exited a sector, the participant controller would contact the pseudo-pilot using the VoIP headset. In the conditions in which routine tasks were automated, the automation would take care of the check-ins and hand-offs using datalink.

Conflict detection. In addition to routine tasks, controllers were asked to deviate from their normal duty of keeping aircraft separated and instead use special keyboard commands to mark aircraft pairs that would lose separation (i.e., come within $5 \mathrm{nmi}$ laterally or $1,000 \mathrm{ft}$ vertically of each other). If the controllers determined a pair of aircraft would eventually lose separation, they would use the "acknowledge" keyboard command AA. This would in turn highlight the two aircraft in blue on the display (Figure 4). If the controllers were unsure if a pair would lose separation, they could use the "monitor" keyboard command MM. This would in turn highlight the two aircraft in yellow. Subsequently, if the controllers felt that an aircraft pair they were monitoring would lose separation, they were asked to highlight the pair using the AA command, which would override the previous MM command. If the controllers felt that a previously highlighted pair was not going to lose separation, they were asked to clear the MM or AA highlighting using the "close" command XX, returning the aircraft to its normal color. Once an aircraft pair lost separation, the participant controllers could clear the MM or AA highlighting if they chose to. On average, each condition contained 11 
conflict pairs with an average of 263 seconds (or 4 minutes 22 seconds) between losses of separation. All conflicts, regardless of whether the handoffs were automated or manual, were the responsibility of the participant controller to detect.

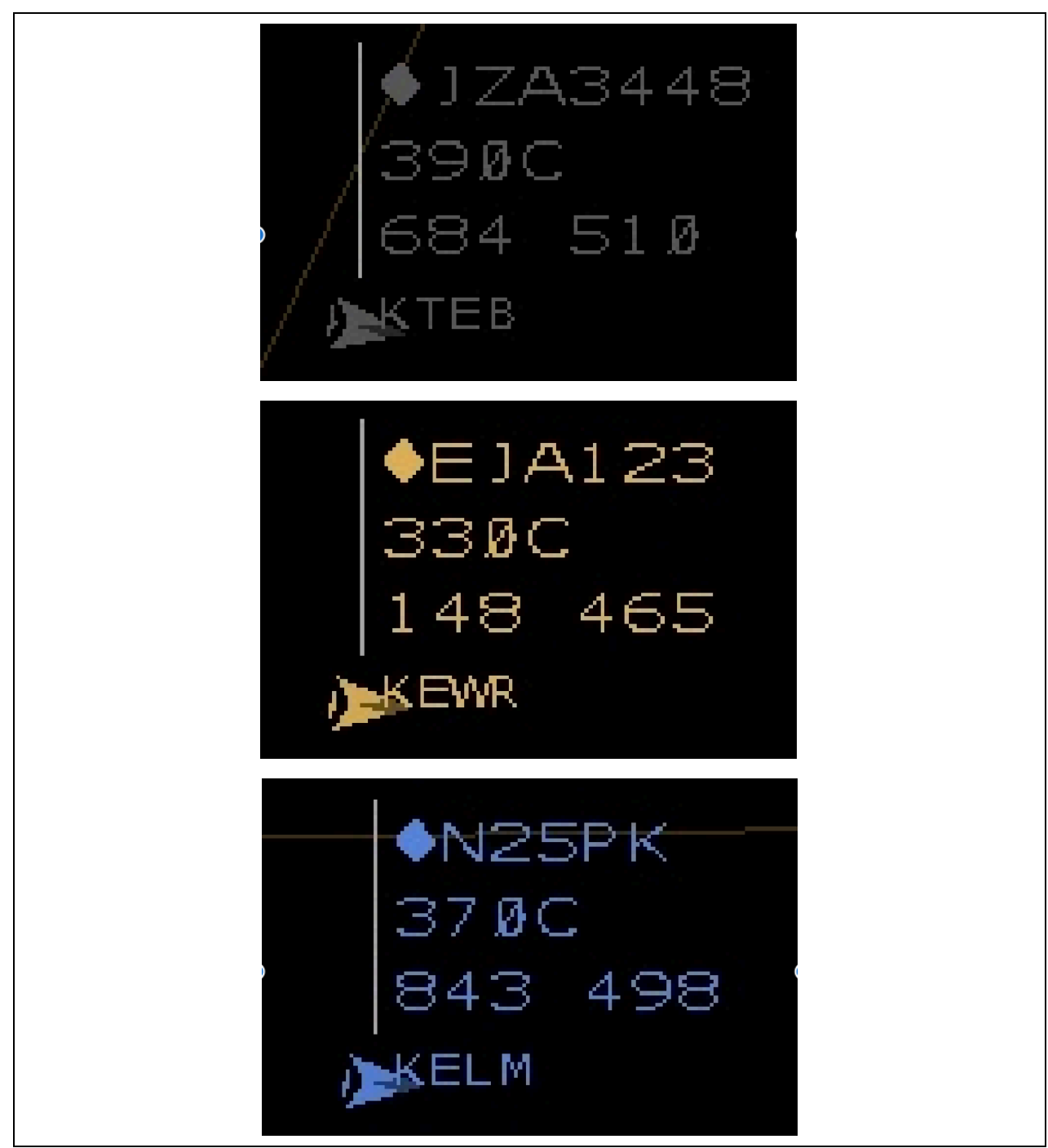

Figure 4. Example of aircraft color changes according to command used. From top to bottom: Top - Nominal aircraft color. Middle MM command used. Bottom - AA command used. 


\section{Measures}

Workload. Workload was measured using the Air Traffic Workload Input Technique (ATWIT), developed by Stein (1985) as an online measure of subjective workload. Over the course of a run, participant controllers were prompted every three minutes to report their level of workload via on-screen buttons displayed at the top of the screen. Every three minutes the workload prompt would go from a muted color to yellow, accompanied by an audible chime to prompt the participant controllers to report their workload on a scale of one to six, with one meaning the workload felt very light and six meaning they felt it was unmanageable. Participant controllers then had 20 seconds to respond before the prompt ended. If a participant controller failed to respond to a workload prompt, the researchers followed convention and assumed it was because they were too busy (i.e. experiencing high workload) (Stein, 1985). Therefore, the maximum workload score of 6 replaces missed scores for a total of 20 workload responses per participant. Figure 5 is an example of what the participant controllers would see normally and every three minutes when prompted to report their workload. The top image shows what the workload prompt looks like normally while the bottom image shows what the workload prompt looks like while waiting for the participant to respond. Figure 6 is the workload briefing material from the original study that presents the level of workload alongside descriptions for each level. 


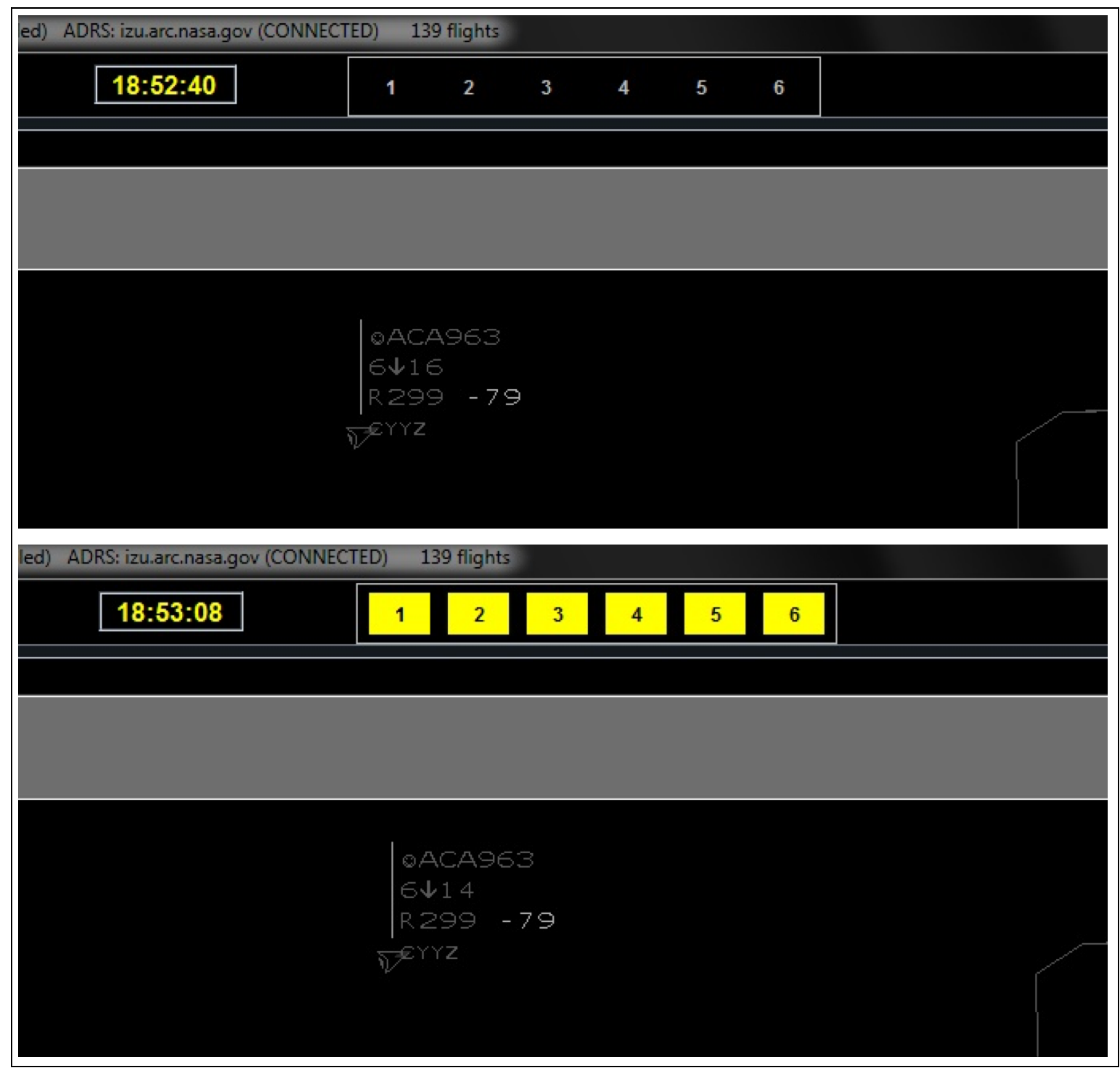

Figure 5. Example of the Air Traffic Workload Input Technique (ATWIT) implemented in MACS. 


\section{Workload Rating Scale}

- Workload: All the physical and mental effort you must exert to do your job, including maintaining the "picture," planning, coordinating, decision making, communicating, and whatever else is required to maintain safe and expeditious traffic flow.



ᄃ

ह 2 - low workload - light traffic - time to give best routes - time to talk

- 3 - somewhat low workload - mostly engaged, in the groove - firm grasp of the flick - proactively looking for conflicts - still provide services

- 4 - somewhat high workload - fully engaged, mostly in the groove - still have the flick - proactive most of the time but focusing more on the separation management over providing services or other tasks with less priority

- 5 - high workload - having trouble keeping the flick - working reactively instead of proactively - relying heavily on automation tools

- 6 - very high workload - on the verge of losing the flick - reactive and scramble mode - falling behind in routine tasks - cannot take on any additional tasks

- Remember that your rating is intended to reflect your workload at the moment you are prompted, not your general appraisal of workload for the whole scenario

- Workload is a very important measure for data analysis please try to respond to every prompt

Figure 6. Participant brief with description of workload experienced and corresponding workload level. 
Conflict detection performance. Conflict detection performance was evaluated based on hit/miss percentage and detection time. Actual conflicts were determined based on logs from each run, which contained the list of aircraft pair that lost separation within the sector. Hits are defined as the earliest MM or AA for a specific conflict pair. A miss is counted if no response was recorded. If no response was recorded in the log, each miss was verified by viewing the video capture of the ATC display for the conflict pair in question. Hits and misses are totaled as a within-group variable and reported as a percentage.

One measure of performance for conflict detection used in the literature is advanced notification time (ANT), wherein performance is measured by how far out a participant controller saw a conflict by taking the time an aircraft pair lost separation and subtracting the detection time. This yields the number of seconds that represent how far away (in time and space) a controller saw a conflict before it became a problem (i.e., lost separation). Instances where participant controllers did not detect a conflict before LOS received an ANT score of 0. Participant controllers' ANT scores were averaged across runs yielding a single score per participant for a total of eight scores per condition.

\section{Conditions}

The present study used a repeated-measures design with four conditions representing two independent variables with two levels each. The four conditions comprised level of air traffic density and routine task support (RTS; see Table 1). Specifically, the density conditions included current-day levels of air traffic or $20 \%$ above current-day levels of air traffic, while RTS conditions included automation that was absent (routine tasks were 
performed manually by the participant controller) or present (routine tasks were automated).

Table 1

Condition Breakdown

\section{Density}

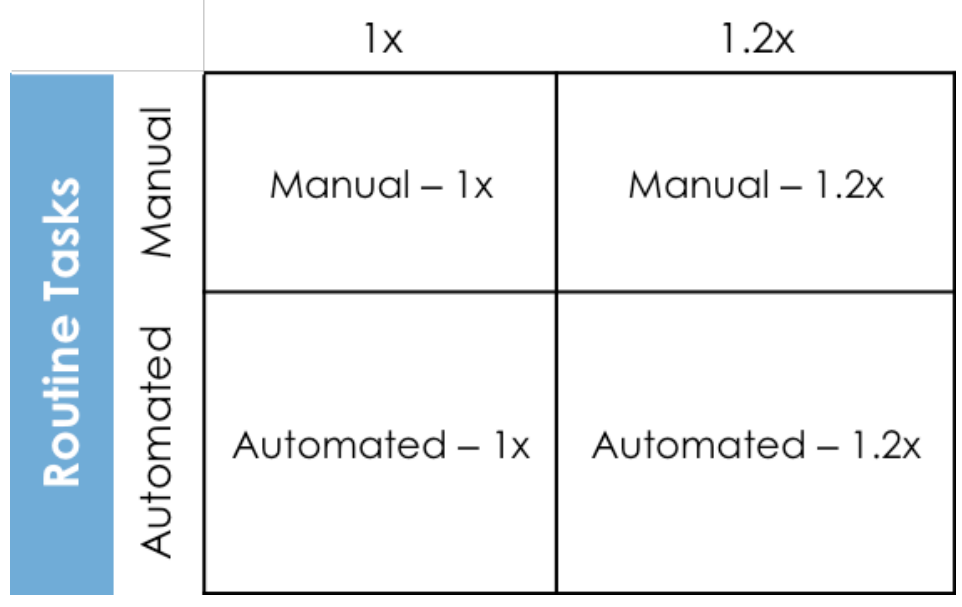

\section{Procedures}

Participant controllers were responsible for managing the simulated air traffic in the experimental sector for the duration of the run. Each participant controller managed his or her own simulated air traffic, separate from one another. Runs lasted $60 \mathrm{~min}$, followed by a questionnaire and break. Each run represented an experimental condition. Runs were presented in a randomized and counterbalanced fashion across participants. Prior to the first run, researchers briefed the participant controllers on responding to the workload prompt and the workload level corresponding to each response value. At the beginning of each run, participant controllers were briefed on which tasks were their responsibility or the responsibility of the automation. In all conditions, participant controllers were 
responsible for detecting and marking conflicts without resolving them. For a more

detailed explanation of the procedures see Mercer et al. (2017) and Mercer et al. (2016).

\section{Analysis}

The goal of the current study is to examine whether automating of routine tasks effects conflict detection performance in both current-day and beyond current-day traffic levels. Specifically, the statistical analyses were run for the following hypotheses: a) average workload will increase as a factor of traffic density, (b) within the current-day (1x) traffic density, average workload will be reduced when routine tasks are automated as compared to when performed manually by the controllers, and; (c) within the higher (1.2x) traffic density, conflict detection performance (measured by average ANT and percent hit/misses) will be better when routine tasks are automated as compared to when they are performed manually by the controller. Two-way, repeated measures ANOVA was used to compare ANT and workload across four conditions: two levels of RTS (manual or automated) and two levels of density (1x or 1.2x). Simple main effects were computed for the hypotheses at each traffic density level. Statistical analysis of the data was done using IBM SPSS Statistics Version 24 (IBM® SPSS® Statistics, 2016). 


\section{Results}

Each run started with a smaller number of aircraft, then increased to the condition's full traffic density shortly thereafter. For this reason, the median number of aircraft is more representative of the number of aircraft participant controllers encountered. Air traffic density of the scenarios consisted of two levels: current-day density (1x density), with an average of 11.5 aircraft and a median of 12.5 , and higher than current-day traffic levels (1.2x traffic density), with an average of 15.09 aircraft and a median of 14.56 (Figure 7). On average, participant controllers in the $1 \mathrm{x}$ density trials encountered 9.5 conflicts in the manual RTS trials and 9 conflicts in the automated RTS trials. In the $1.2 x$ density trials, participant controllers encountered 11 conflicts in the manual RTS trials and 11.5 in the automated RTS trials, on average.

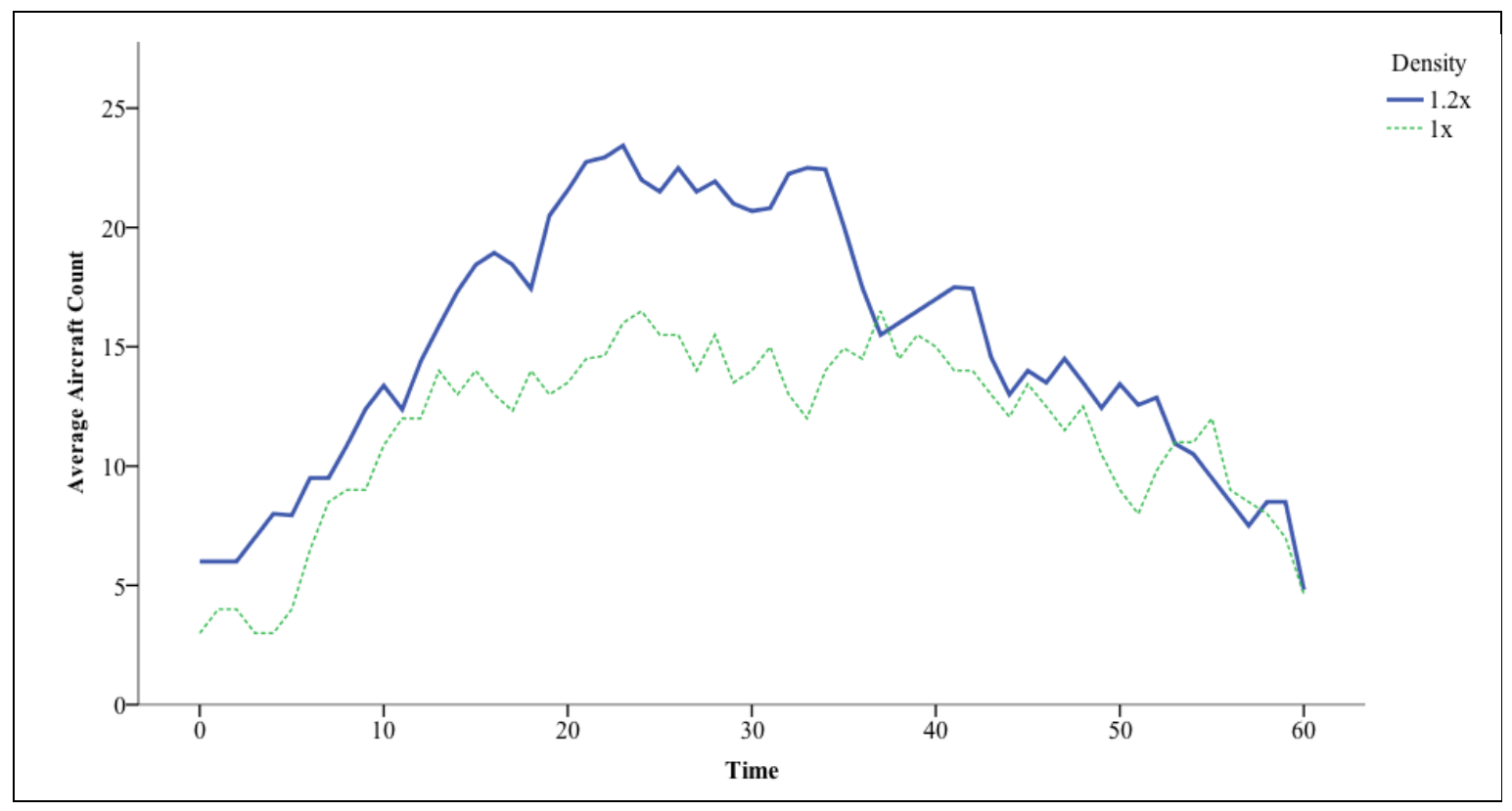

Figure 7. Plot of traffic density for $1 \mathrm{x}$ and $1.2 \mathrm{x}$. 


\section{Workload}

The overall average workload reported was $3.15(S D=0.72)$. Participant controllers reported an average workload of $2.92(S D=0.72)$ in the $1 \mathrm{x}$ density condition and an average of $3.39(S D=0.66)$ in the $1.2 x$ condition. For RTS, they reported an average workload of $3.30(S D=0.84)$ in the manual condition and $3.01(S D=0.84)$ in the automated condition. Figure 8 shows the average workload by density and RTS. Figure 9 contains the frequencies of workload ratings grouped by traffic density and RTS.

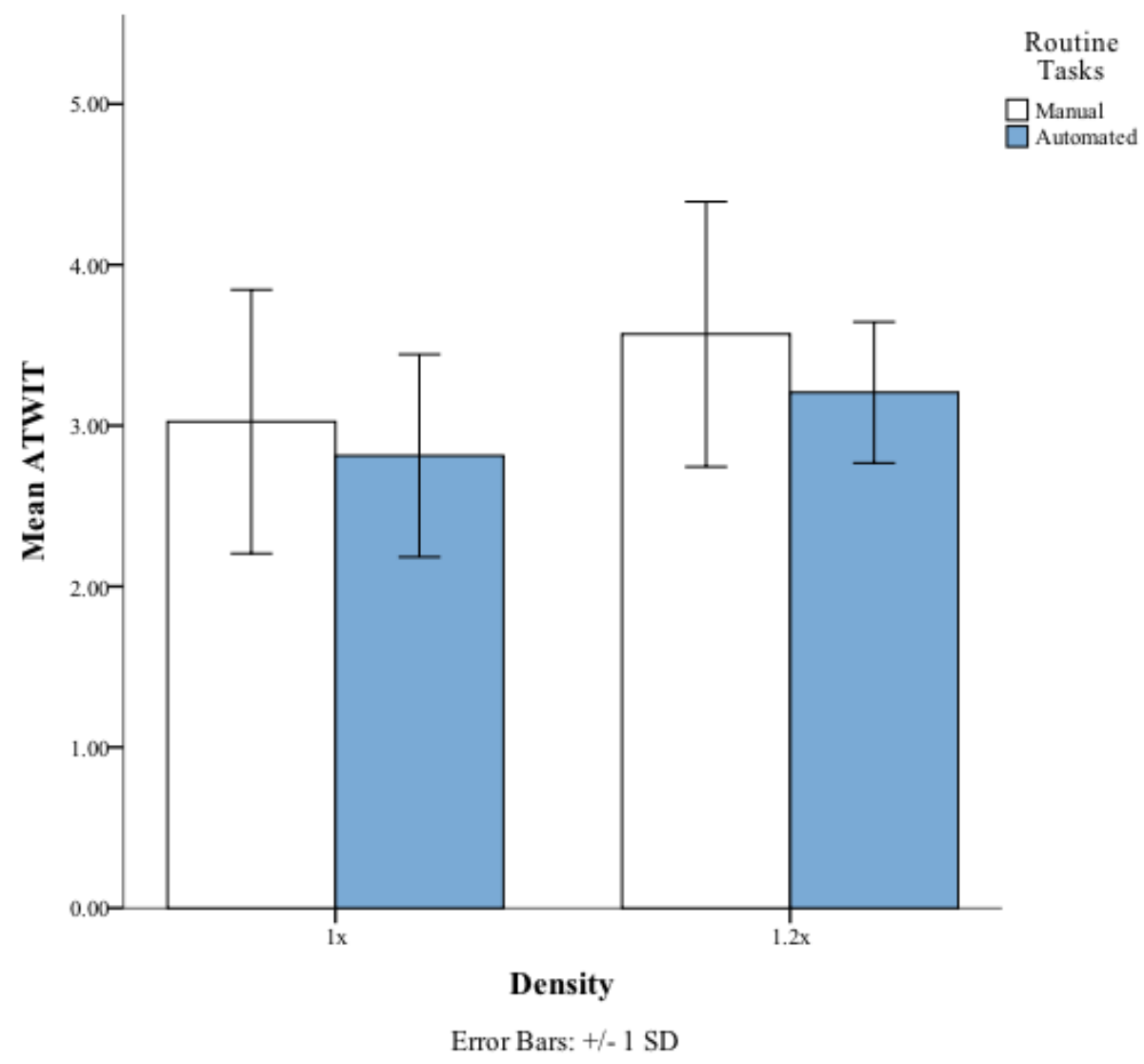

Figure 8. Mean workload (ATWIT) across the two levels of density and routine tasks. Error bars represent standard deviation. 
a)

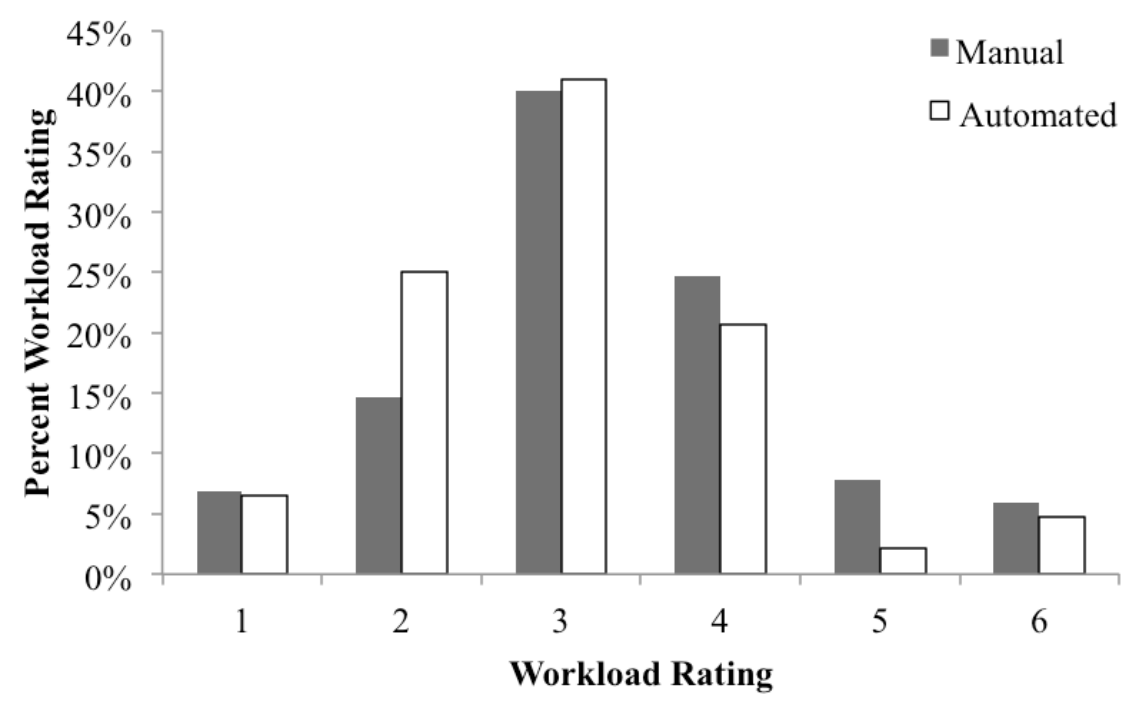

b)

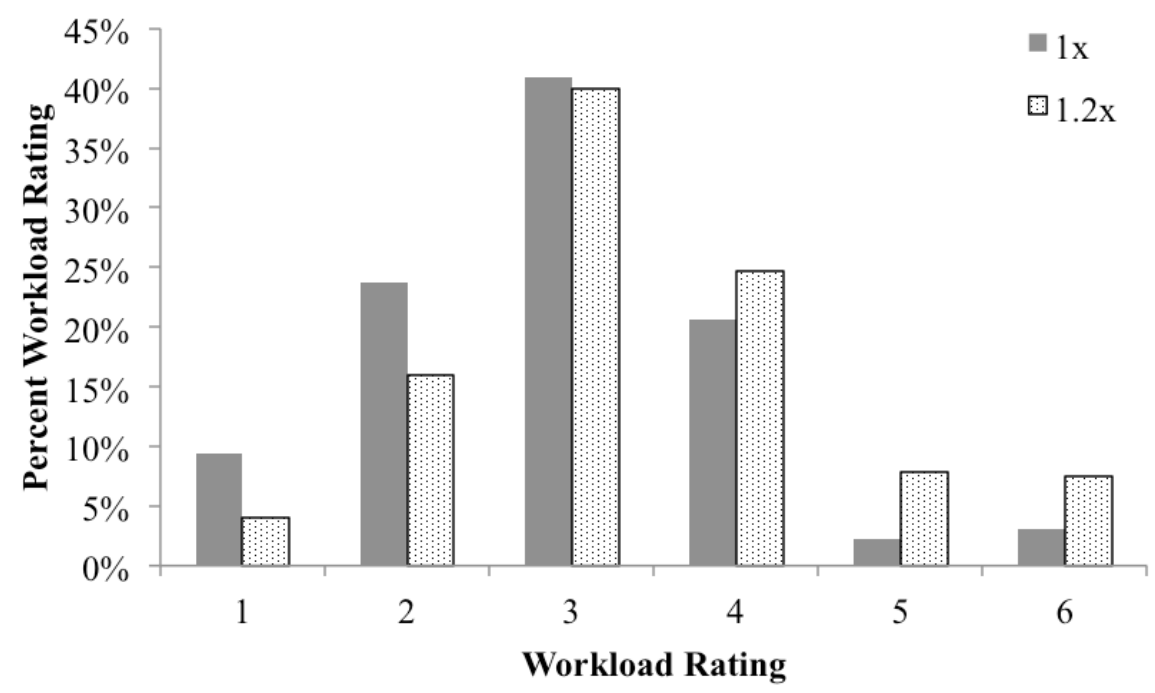

Figure 9. Frequency of a) workload by routine task and b) workload by traffic density. 
A two-way repeated measures ANOVA was used to examine the effects of density and RTS on workload. Table 2 contains the means and standard deviations for each condition. The ANOVA showed a significant main effect of density, $F(1,7)=9.90, p<$ $.05, d=1.147$. No significant main effect for RTS was found, $F(1,7)=4.40, p=.07$. No significant interaction between density and RTS was found, $F(1,7)=2.08, p=.19$. The simple main effects for each independent variable are examined for workload. Table 3 summarizes the results. Of these comparisons, two reached significance.

Table 2

Descriptive Statistics of Workload Ratings

\begin{tabular}{llcc}
\hline Routine Tasks & Density & $M$ & $S D$ \\
\hline Manual & $1 \mathrm{x}$ & 3.03 & 0.82 \\
& $1.2 \mathrm{x}$ & 3.57 & 0.82 \\
\hline Automated & $1 \mathrm{x}$ & 2.81 & 0.63 \\
& $1.2 \mathrm{x}$ & 3.21 & 0.44 \\
\hline
\end{tabular}

Table 3

Simple Main Effects for Each Level of Routine Tasks and Density for workload

\begin{tabular}{lcccccc}
\hline \multicolumn{1}{c}{ Routine } & \multicolumn{2}{c}{$F$} & & \\
\multicolumn{1}{c}{ Tasks } & \multicolumn{2}{c}{ Density Pair } & $F$ & $d f$ & $p$ & $d$ \\
\hline Manual & $1 \mathrm{x}$ & $1.2 \mathrm{x}$ & $10.81^{*}$ & 1,7 & .01 & 1.16 \\
Automated & $1 \mathrm{x}$ & $1.2 \mathrm{x}$ & $6.91^{*}$ & 1,7 & .03 & 1.04 \\
\cline { 2 - 7 } \multicolumn{1}{c}{ Density } & \multicolumn{2}{c}{ Routine Task Pair } & & & & \\
\hline $1 \mathrm{x}$ & Manual & Automated & 4.69 & 1,7 & .07 & 1.09 \\
$1.2 \mathrm{x}$ & Manual & Automated & 3.94 & 1,7 & .09 & 1.00 \\
\hline$* p<.05$ & & & & &
\end{tabular}




\section{Conflict Detection}

Participant controllers had a mean ANT of $273.91(S D=69.00)$. Mean ANT in the 1x density condition $(M=249.70, S D=65.24)$ is lower than in the $1.2 x$ condition $(M=$ 295.12, $S D=60.61)$. Figure 10 shows mean ANT by density and RTS. It appears there is not much difference between the mean ANT in the manual RTS condition $(M=$ 275.53, $S D=71.81)$ and the automated RTS condition $(M=272.29, S D=51.63)$.

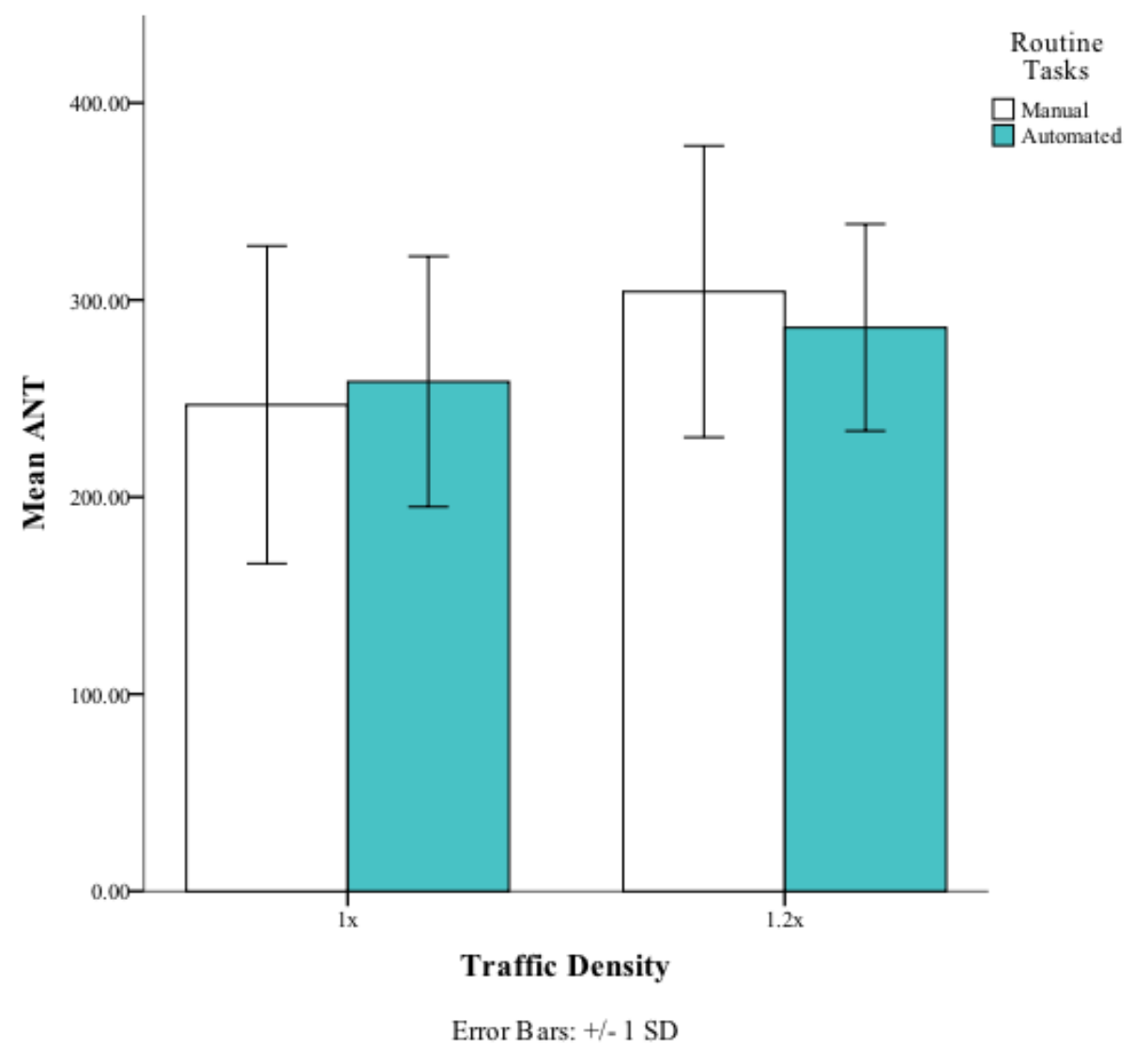

Figure 10. Mean ANT across the two levels of density and routine tasks. Error bars represent standard deviation. 
A two-way repeated measures ANOVA was used to examine the effects of density and RTS on ANT. Table 4 contains the means and standard deviations for each condition. The ANOVA showed a significant main effect of density, $F(1,7)=8.547, p<.05, d=$ 1.11. No significant main effect for RTS was found, $F(1,7)=.084, p=.78, d=.02$. Additionally, the interaction between density and RTS was non-significant, $F(1,7)=$ $1.267, p=.297$.

Exploration of the simple main effects for both independent variables is used to test the hypotheses about the interaction between density and RTS. Table 5 summarizes the results. Only the comparison between $1 \mathrm{x}$ and $1.2 \mathrm{x}$ density in the manual RTS condition reached significance at the .05 level.

Table 4

Descriptive Statistics of ANT Scores

\begin{tabular}{llcc}
\hline Routine Tasks & Density & $M$ & $S D$ \\
\hline Manual & $1 \mathrm{x}$ & 246.81 & 80.61 \\
& $1.2 \mathrm{x}$ & 304.26 & 73.94 \\
\hline Automated & $1 \mathrm{x}$ & 258.56 & 63.55 \\
& $1.2 \mathrm{x}$ & 286.01 & 52.45 \\
\hline
\end{tabular}

Table 5

Simple Main Effects for Each Level of Routine Tasks and Density for Score

\begin{tabular}{lcccccc}
\hline \multicolumn{1}{c}{$\begin{array}{c}\text { Routine } \\
\text { Tasks }\end{array}$} & \multicolumn{2}{c}{ Density Pair } & $F$ & $d f$ & $p$ & $d$ \\
\hline Manual & $1 \mathrm{x}$ & $1.2 \mathrm{x}$ & $8.00^{*}$ & 1,7 & .03 & 1.01 \\
Automated & $1 \mathrm{x}$ & $1.2 \mathrm{x}$ & 2.07 & 1,7 & .19 & 0.52 \\
\cline { 2 - 7 } & & & & & & \\
\multicolumn{1}{c}{ Density } & \multicolumn{2}{c}{ Routine Task Pair } & & & & \\
\hline $1 \mathrm{x}$ & Manual & Automated & .35 & 1,7 & .58 & 0.22 \\
$1.2 \mathrm{x}$ & Manual & Automated & 1.61 & 1,7 & .24 & 0.53 \\
\hline$* p<.05$ & & & & & &
\end{tabular}


Participant controllers detected more conflicts (96\%) with automated RTS than with manual RTS (91\%). Participant controllers also detected more conflicts in the $1 \mathrm{x}$ density $(96 \%)$ than in the $1.2 \mathrm{x}$ density $(92 \%)$, illustrated in Figure 11. Figure 12 shows the conflict detection frequencies for each condition. Additionally, Figure 13 presents a summary of the workload and conflict detection results.

a)

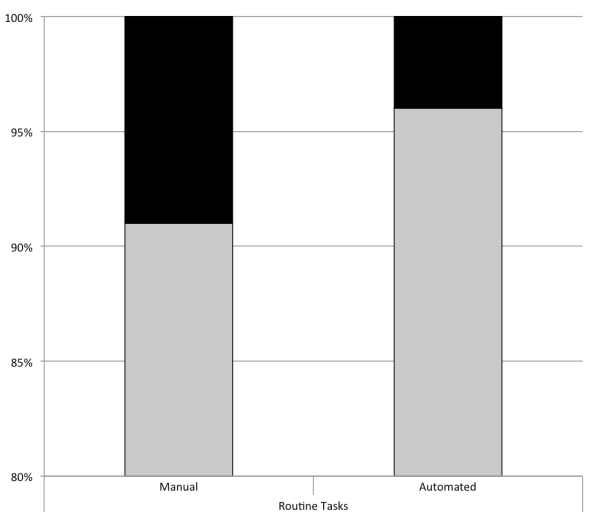

b)

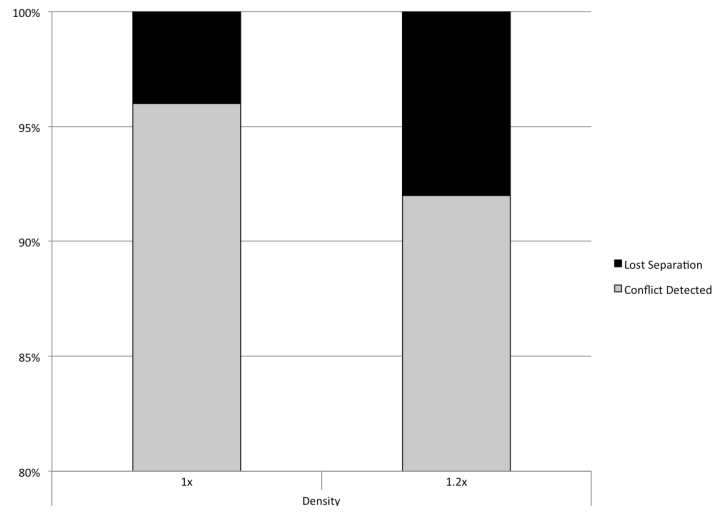

Figure 11. Conflict detection rate a) by routine tasks and b) by density



Figure 12. Conflict detection rate by condition. 


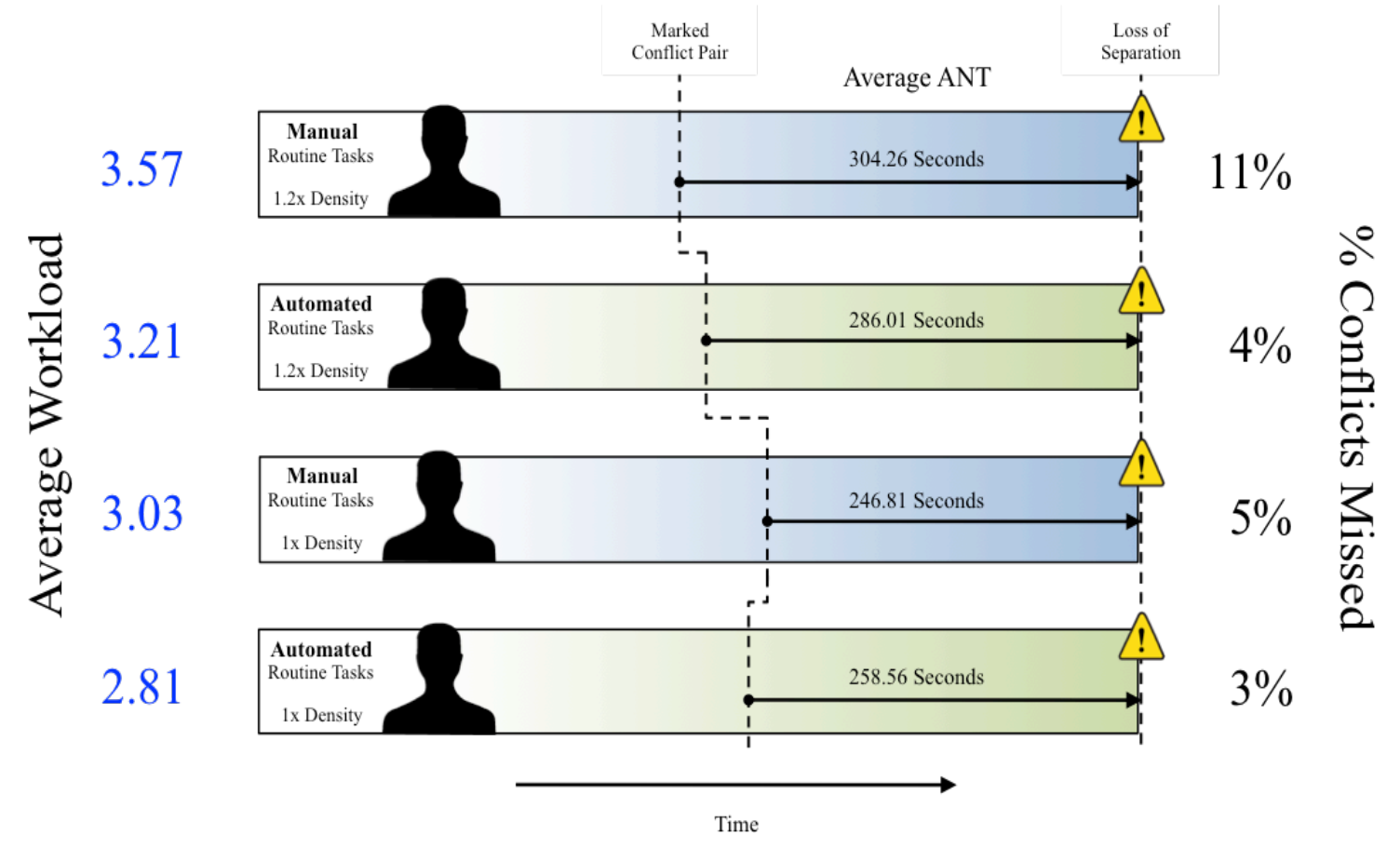

Figure 13. Summary of results. 


\section{Discussion}

\section{Hypothesis 1}

Hypothesis 1 was the controllers' subjective workload would increase when traffic density increased. A significant difference in ATWIT scores between the 1x and 1.2x densities supports Hypothesis 1. Participant controllers also experienced the highest level of workload in the 1.2x density, reporting workload scores of 5 and 6 almost twice as often as compared to the $1 \mathrm{x}$ density. This indicates that participant controllers experienced levels of workload that put them in a reactive, rather than proactive, mode of managing traffic, were at risk of falling behind on tasks, and had reached the maximum number of tasks they could manage. This result is consistent with previous studies that also found a significant impact of traffic density on air traffic controller workload (Glaster et al., 2001; Kopardekar et al., 2009; Lee et al., 2007; Metzger \& Parasuraman, 2001; Willems \& Truitt, 1999). The significant difference in workload experienced by participant controllers also validates the experimental conditions, with high traffic density actually being significantly more work than current-day traffic density.

\section{Hypothesis 2}

Hypothesis 2 was at the $1 \mathrm{x}$ density, controllers' subjective workload would be reduced when routine tasks were automated compared to when routine tasks were manual. Support for Hypothesis 2 is inconclusive; there was no significant difference in ATWIT scores between manual and automated routine tasks within the $1 \mathrm{x}$ density. However, the results of the simple main effect show a nearly significant difference, and 
when taken with the large effect size, indicate the lower average workload when routine tasks were automated may have been a result of the automation and not chance.

The literature has mixed results when it comes to the effects of automation on workload. Some forms of automation reduce workload more than others (Manzey et al., 2012; Parasuraman et al., 2000). One possible explanation of the results is that the level of workload in the 1x density could not be substantially reduced because the controllers' workload was already low. With their workload low, the participant controllers may have taken steps to ensure their workload did not decrease too much in an effort to avoid underload. This explanation is supported by Prevot et al., (2008), who found that when given the option, participant controllers decreased their use of automated support in low density.

\section{Hypothesis 3}

Hypothesis 3 was that at the $1.2 \mathrm{x}$ density, controllers' conflict detection performance would be better when routine tasks were automated, as compared to when routine tasks were manual. Support for Hypothesis 3 is inconclusive; there was no significant difference in ANT between automated and manual routine tasks in the 1.2x density. Detecting conflicts farther away from loss of separation has traditionally been interpreted as better performance in the literature (Glaster et al., 2001; Metzger \& Parasuraman, 2001). Contrary to previous literature, participant controllers in the current study consistently detected conflicts closer to loss of separation in the $1 \mathrm{x}$ density conditions and farther away in the $1.2 \mathrm{x}$ condition. When comparing the ANT of each condition to the corresponding conflict detection rates, it appears at first that the two measures contradict 
each other. One explanation that satisfies both results is the participant controllers, either in an effort to maintain engagement or as a result of excess bandwidth, allocated more resources to monitoring a potential conflict as the flights progressed. Controllers must consider the cost of moving aircraft on their own attentional resources and the potential to increase complexity of the sector. In an operational setting, this could serve as motivation to be certain that an aircraft pair is truly in conflict before issuing a maneuver. Participant controllers in the current study were instructed to mark a potential conflict pair with 'MM' if they were uncertain, and 'AA' when they felt certain. However, if the participant controllers in the current study did not follow those instructions and instead marked conflict pairs when they would normally issue a resolution (which would be a much more natural sequence of event to them), this would explain why the detection times are the opposite of what was expected. Given the mixed results, the remaining discussion of conflict detection performance will not be qualified as "better" or "worse" and instead the differences are discussed.

Although there was not a significant difference in ANT at the 1.2x density, the simple main effect of density had a significant effect on ANT when routine tasks were manual; it did not have a significant effect when routine tasks were automated. Additionally, the difference in workload between automated and manual routine tasks in the $1.2 \mathrm{x}$ density is nearly significant, with lower workload reported when routine tasks were automated. Conflict detection also differed between automated and manual routine tasks. Participant controllers in the $1 \mathrm{x}$ manual routine task condition went from missing $5 \%$ of the conflicts to $11 \%$ of the conflicts in $1.2 \mathrm{x}$ manual routine task condition, an increase of $6 \%$. In 
contrast, participant controllers in the $1 \mathrm{x}$ automated routine task condition missed $3 \%$ of the conflicts and $4 \%$ in the $1.2 \mathrm{x}$ automated routine task condition. Taken together, results suggest that automation of routine tasks did alleviate controller workload and improve conflict detection performance in increased traffic levels compared to manual routine tasks.

The literature has mixed results when it comes to the effects of automation on performance. What is clear is automation will differentially impact performance depending on the task, the number of sub-tasks supported by the automation (Kaber et al., 2007; Parasuraman et al., 2000), and whether automation of the task or sub-tasks disrupts the controller's ability to maintain the picture by creating a less engaging situation (Balfe et al., 2015; Endsley and Kiris, 1995; Manzey et al., 2012). 


\section{Conclusion}

Air traffic controllers are constantly scanning their sector, employing a variety of cognitive strategies best suited for the situation at hand. When the situation evolves and the controller anticipates an increase in workload, they will change strategies to reduce the amount of information into meaningful chunks, thereby reducing workload. It would make sense then, that the inverse is true: in situations where workload is low, and engagement is declining, air traffic controllers again change strategies to keep themselves engaged thus maintaining the "picture" and therefore performance. This skill is acquired with experience, honed over time to utilize the personal strengths, task-relevant skills, and to compensate for weaknesses of the individual controller. Future research should examine the nature of the contribution sub-tasks make to performance as a whole. Specifically, what is it about routine tasks (and equivalent tasks) in low workload situations that controllers benefit from later on? How are these elements incorporated into the strategies used or how do they facilitate the real-time strategy changes made by controllers? The results of the current study further support the notion that routine tasks are more than just busy work; controllers differentially utilize such tasks as part of a greater strategy to maintain awareness, engagement, and ultimately, safety. 


\section{References}

Balfe, N., Sharples, S., \& Wilson, J. R. (2015). Impact of automation: measurement of performance, workload and behaviour in a complex control environment. Applied Ergonomics, 47, 52-64.

Bureau of Transportation Statistics. (2016a). 2015 U.S.-Based Airline Traffic Data. Retrieved from https://www.bts.gov/newsroom/2015-us-based-airline-traffic-data (http://archive.li/dOG4Z)

Bureau of Transportation Statistics. (2016b). 2017 Traffic Data for U.S Airlines and Foreign Airlines U.S. Flights. Retrieved from https://www.bts.gov/newsroom/2017-traffic-data-us-airlines-and-foreign-airlinesus-flights (http://archive.li/CnA0y)

Department of Transportation, \& FAA. (2016). The Future of the NAS (p. 44). Retrieved from https://www.faa.gov/nextgen/

Edwards, T., Homola, J., Mercer, J., \& Claudatos, L. (2016). Multifactor interactions and the air traffic controller: The interaction of situation awareness and workload in association with automation. IFAC-PapersOnLine, 49(19), 597-602. https://doi.org/10.1016/j.ifacol.2016.10.623

Endsley, M. R., \& Kiris, E. O. (1995). The out-of-the-loop performance problem and level of control in automation. Human Factors, 37(2), 381-394.

FAA Office of NextGen. (2016). NextGen Implementation Plan. Retrieved from www.faa.gov/nextgen

Federal Aviation Administration, Mission support services. (2017, August 30). Air Traffic Control (FAA Order JO 7110.65X). Retrieved from https://www.faa.gov/documentLibrary/media/Order/7110.65W_Bsc_w_Chg_13_dtd_4-27-17.pdf

Galster, S. M., Duley, J. A., Masalonis, A. J., \& Parasuraman, R. (2001). Air traffic controller performance and workload under mature free flight: Conflict detection and resolution of aircraft self-separation. The International Journal of Aviation Psychology, 11(1), 71-93.

IBM ${ }^{\circledR}$ SPSS $®$ Statistics. (2016). (Version 24).

Kaber, D. B., Perry, C. M., Segall, N., \& Sheik-Nainar, M. A. (2007). Workload state classification with automation during simulated air traffic control. The International Journal of Aviation Psychology, 17(4), 371-390. 
Kopardekar, P., Prevot, T., \& Jastrzebski, M. (2008). Traffic complexity measurement under higher levels of automation and higher traffic densities. In AIAA Guidance, Navigation and Control Conference and Exhibit (Vols. 1-0). American Institute of Aeronautics and Astronautics. https://doi.org/10.2514/6.2008-7397

Lee, P. U., Mercer, J., \& Callantine, T. (2007). Examining the moderating effect of workload on controller task distribution. In International Conference on Engineering Psychology and Cognitive Ergonomics (pp. 339-348). Springer.

Majumdar, A., \& Ochieng, W. (2002). Factors affecting air traffic controller workload: Multivariate analysis based on simulation modeling of controller workload. Transportation Research Record: Journal of the Transportation Research Board, (1788), 58-69.

Manzey, D., Reichenbach, J., \& Onnasch, L. (2012). Human performance consequences of automated decision aids: the impact of degree of automation and system experience. Journal of Cognitive Engineering and Decision Making, 6(1), 57-87. https://doi.org/10.1177/1555343411433844

Mercer, J., Gabets, C., Gomez, A., Edwards, T., Bienert, N., Claudatos, L., \& Homola, J. (2017). How important is conflict detection to the conflict resolution task? In N. A. Stanton, S. Landry, G. Di Bucchianico, \& A. Vallicelli (Eds.), Advances in Human Aspects of Transportation (Vol. 484, pp. 103-115). Cham: Springer International Publishing. https://doi.org/10.1007/978-3-319-41682-3_9

Mercer, J., Gomez, A., Gabets, C., Bienert, N., Edwards, T., Martin, L., ... Homola, J. (2016). Impact of automation support on the conflict resolution task in a humanin-the-loop air traffic control simulation. IFAC-PapersOnLine, 49(19), 36-41. https://doi.org/10.1016/j.ifacol.2016.10.458

Metzger, U., \& Parasuraman, R. (2001). The role of the air traffic controller in future air traffic management: an empirical study of active control versus passive monitoring. Human Factors, 43(4), 519-528.

Nolan, M. (2010). Fundamentals of air traffic control (5th ed.). Cengage learning.

Parasuraman, R., Sheridan, T. B., \& Wickens, C. D. (2000). A model for types and levels of human interaction with automation. IEEE Transactions on Systems, Man, and Cybernetics-Part A: Systems and Humans, 30(3), 286-297.

Prevot, T. (2002). Exploring the many perspectives of distributed air traffic management: The Multi Aircraft Control System MACS. In Proceedings of the HCI-Aero (pp. 149-154). Retrieved from https://vvvvw.aaai.org/Papers/HCI/2002/HCI02024.pdf 
Prevot, T., Homola, J., \& Mercer, J. (2008). Human-in-the-loop evaluation of groundbased automated separation assurance for NEXTGEN. In The 26th Congress of ICAS and 8th AIAA ATIO (p. 8885). Retrieved from http://arc.aiaa.org/doi/pdf/10.2514/6.2008-8885

Prevot, T., \& Mercer, J. (2007). MACS: A simulation platform for today's and tomorrow's air traffic operations. American Institute of Aeronautics and Astronautics. https://doi.org/10.2514/6.2007-6556

Prevot, T., Smith, N. M., Palmer, E., Callantine, T. J., Lee, P. U., Mercer, J., ... Cabrall, C. (2014). An overview of current capabilities and research activities in the airspace operations laboratory at NASA Ames Research Center. American Institute of Aeronautics and Astronautics. https://doi.org/10.2514/6.2014-2860

Seamster, T. L., Redding, R. E., Cannon, J. R., Ryder, J. M., \& Purcell, J. A. (1993). Cognitive task analysis of expertise in air traffic control. The International Journal of Aviation Psychology, 3(4), 257-283.

Sipe, A., \& Moore, J. (2009). Air traffic functions in the NextGen and SESAR airspace. In Digital Avionics Systems Conference, 2009. DASC'09. IEEE/AIAA 28th (pp. 2. A. 6-1-2. A. 6-7). IEEE. Retrieved from http://ieeexplore.ieee.org/abstract/document/5347554/

Stein, E. S. (1985). Air traffic controller workload: An examination of workload probe (Technical Note No. DOT/FAA/CT-TN84/24). Atlantic City International Airport: Federal Aviation Administration Technical Center.

Willems, B., \& Truitt, T. R. (1999). Implication of Reduced Involvement in En Route Air Traffic Control (Technical Note No. DOT/FAA/CT-TN99/22) (p. 163). 